\title{
Streamflow variability over the 1881-2011 period in northern Québec: comparison of hydrological reconstructions based on tree rings and geopotential height field reanalysis
}

\author{
Pierre Brigode $^{1,2, a}$, François Brissette ${ }^{1}$, Antoine Nicault ${ }^{3}$, Luc Perreault ${ }^{4}$, Anna Kuentz ${ }^{5, b}$, Thibault Mathevet ${ }^{5}$, and \\ Joël Gailhard ${ }^{5}$ \\ ${ }^{1}$ École de Technologie Supérieure, Université du Québec, Montréal, Canada \\ ${ }^{2}$ Ouranos Consortium, Montréal, Canada \\ ${ }^{3}$ ECCOREV, Aix-en-Provence, France \\ ${ }^{4}$ Institut de recherche d'Hydro-Québec (IREQ), Varennes, Canada \\ ${ }^{5}$ DTG, Electricité de France, Grenoble, France \\ anow at: Université Côte d'Azur, CNRS, OCA, IRD, Géoazur \\ b now at: SMHI, Norrköping, Sweden
}

Correspondence to: Pierre Brigode (pierre.brigode@unice.fr)

Received: 8 January 2016 - Published in Clim. Past Discuss.: 27 January 2016

Revised: 27 July 2016 - Accepted: 29 July 2016 - Published: 6 September 2016

\begin{abstract}
Over the last decades, different methods have been used by hydrologists to extend observed hydro-climatic time series, based on other data sources, such as tree rings or sedimentological datasets. For example, tree ring multiproxies have been studied for the Caniapiscau Reservoir in northern Québec (Canada), leading to the reconstruction of flow time series for the last 150 years. In this paper, we applied a new hydro-climatic reconstruction method on the Caniapiscau Reservoir and compare the obtained streamflow time series against time series derived from dendrohydrology by other authors on the same catchment and study the natural streamflow variability over the 1881-2011 period in that region. This new reconstruction is based not on natural proxies but on a historical reanalysis of global geopotential height fields, and aims firstly to produce daily climatic time series, which are then used as inputs to a rainfall-runoff model in order to obtain daily streamflow time series. The performances of the hydro-climatic reconstruction were quantified over the observed period, and showed good performances, in terms of both monthly regimes and interannual variability. The streamflow reconstructions were then compared to two different reconstructions performed on the same catchment by using tree ring data series, one being focused on mean annual flows and the other on spring floods. In terms of mean
\end{abstract}

annual flows, the interannual variability in the reconstructed flows was similar (except for the 1930-1940 decade), with noteworthy changes seen in wetter and drier years. For spring floods, the reconstructed interannual variabilities were quite similar for the 1955-2011 period, but strongly different between 1880 and 1940. The results emphasize the need to apply different reconstruction methods on the same catchments. Indeed, comparisons such as those above highlight potential differences between available reconstructions and, finally, allow a retrospective analysis of the proposed reconstructions of past hydro-climatological variabilities.

\section{Introduction}

\subsection{Challenge of decadal hydrological variability}

Time series of streamflow observations, which constitute the basis for all hydrological analyses, are generally characterized by a relatively short record period, typically ranging from several years to several decades. In fact, the average length of 6945 daily streamflow series collected by the Global Runoff Data Centre, and available worldwide, is 44 years (GRDC, 2015). The information extracted by hydrologists from these time series (in the form of statistical 
indices, calibration of model parameters, etc.) is generally used for water resource management, for instance for hydropower generation mid- to long-term planning. The short record period is a major issue for hydrologists since it may be insufficient to capture and provide a clear understanding of the decadal variability in hydrological processes. For example, after studying a 90-year-long daily streamflow series of the Po River (Italy), and highlighting significant natural variability at the decadal scale, Montanari (2012) stated that "more research efforts are needed to improve the interpretation of such long-term fluctuations". Studying natural variability requires long instrumental records (typically longer than 100 years), but such long time series are non-existent in remote regions such as northern Québec (Canada). The length (number of years) of 221 observed streamflow time series from Québec - extracted from the (cQ) ${ }^{2}$ (Impact des Changements Climatiques sur l'hydrologie (Q) au Québec) database (Guay et al., 2015) - is shown in Fig. 1b and c, emphasizing that very few series have more than 50 years of data. Hydrological decadal variability is crucial in this region, since it is home to some of the largest hydropower systems in the world; as well, significant interannual inflow variability has been recorded in several Québec catchments (e.g., Perreault et al., 2000, 2007; Jandhyala et al., 2009). The few decades of observations available for this region are not sufficient to allow a robust analysis of multi-decadal hydrological variability and thus raise the issue of the reconstruction of past hydrology, i.e., occurring before the systematic recording of streamflows.

\subsection{Reconstruction of past hydrology}

Over the past decades, different methods have been used by hydrologists to reconstruct natural flows on catchments of interest, depending on available data. These methods may be classified into two groups, according to the temporal resolution of the reconstructed series.

The first group brings together the methods based on long and continuous hydro-climatic series constructed with daily or sub-daily observations and consequently allows the reconstruction of streamflow time series at a fine temporal scale (e.g., daily resolution). When long streamflow series are available for other catchments close to the one under study, classical statistical regressions or other regionalization methods could be applied for the reconstruction (e.g., Hirsch, 1982; Hernández-Henríquez et al., 2010; Arsenault and Brissette, 2014). The paired catchment approach - consisting of calibrating and then using a streamflow-streamflow model could also be used (e.g., Andréassian et al., 2012). When long climatic series (typically covering precipitation and temperature) are available in the studied region, the reconstruction could be done by using a rainfall-runoff model in order to transform the climatic series into streamflow series (e.g., simulation of 124 years of streamflow for the Thames River (UK) by Crooks and Kay, 2015).
The second method is based on continuous or discrete series of paleo-indicators, generally producing reconstructed series at seasonal or annual resolutions (Bradley, 1999). The most natural proxies used for hydrological reconstructions are sediment stratigraphy (e.g., Thorndycraft et al., 2005) and tree ring series (see reviews by Loaiciga et al., 1993; Meko and Woodhouse, 2011). This latter proxy for streamflow reconstruction, referenced as dendrohydrology (Loaiciga et al., 1993), is analyzed in a bid to reconstruct past hydro-climatological variations in a given catchment by studying tree ring width variations among different trees sampled in the same region. Reconstructed streamflow series are obtained by applying either direct or indirect methods. The direct methods aim to link tree ring series with streamflow series through statistical models calibrated over an observation period (e.g., in Tasmania (Australia) by Allen et al., 2015, and in the southeastern United States by Patskoski et al., 2015). The indirect methods aim firstly to reconstruct climatic series, such as temperature or precipitation, and secondly to transform these climatic series into streamflow series through rainfall-runoff models (e.g., in the western US by Gray and McCabe, 2010; Saito et al., 2015). These methods allow the continuous reconstruction of the annual or seasonal water balance of a given region, over long time periods. Additionally, other information could be extracted following tree ring analysis and used to reconstruct discrete chronologies of extreme hydrological events. For example, George and Nielsen (2003) used anatomical tree ring signatures to reconstruct paleofloods of the Red River in Manitoba (Canada).

Recently, dendrohydrological methods have been successfully applied in boreal environments, characterized by a rarity of long hydro-climatological series. For example, Nicault et al. (2014) used tree ring multi-proxies (tree ring widths, tree ring densities and tree ring stable isotope ratios) to produce spring, summer, and annual flow series of the Caniapiscau Reservoir in northern Québec (Canada) for the 18002000 period. On the same catchment, Boucher et al. (2011) used both continuous series (tree ring minimal density measurements) and discrete series (with ice scars due to ice abrasion during floods) to produce spring flood series for the 1850-1980 period. These two reconstructions revealed significant flow variability in this region, in terms of both annual flows and flood frequency. It should be noted that the Caniapiscau Reservoir is the most upstream and one of the largest reservoirs of the La Grande complex, which is one of the biggest hydropower generation complexes in the world, with a total installed generating capacity of $17418 \mathrm{MW}$. Decadal hydro-climatological variability in this region thus provides important information concerning the long-term planning of hydropower generation.

\subsection{Scope of paper}

Although the above-mentioned hydrological reconstructions were associated with good verification statistics on the cali- 

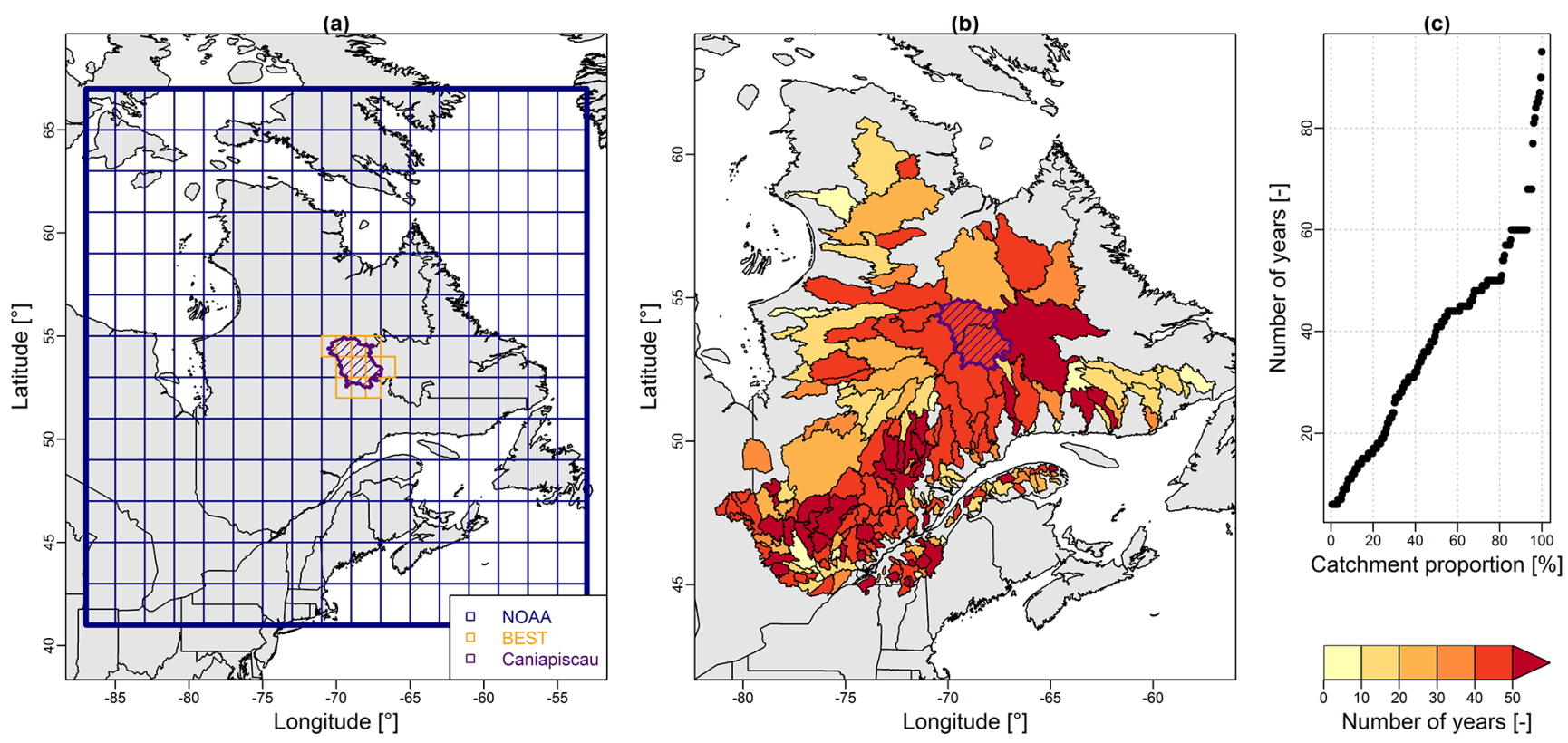

Figure 1. (a) Datasets used for the hydro-climatic reconstruction: the extension of the 20CR grid points used is shown in blue, while the BEST grid points used are highlighted in purple. The Caniapiscau Reservoir catchment is plotted in purple. (b) Spatial distribution and (c) distribution of the length (number of years) of the observed streamflow series for 211 catchments in Québec, extracted from the (cQ) ${ }^{2}$ database (Guay et al., 2015).

bration period, the lack of observed streamflow data did not allow a rigorous independent verification of those reconstructions. An alternative solution involved carrying out new reconstructions based on different proxies and different methods and then, as an additional verification step, analyzing the consistency between the different reconstructions. Comparisons of streamflow reconstruction methods are rare in the literature, and the Caniapiscau Reservoir catchment offers an interesting case study since various tree ring reconstructions have been performed there. Thus, our objective is to apply a new reconstruction method on the Caniapiscau Reservoir in order to compare the obtained streamflow series with series obtained by dendrohydrology and to study the observed streamflow variability over the 1881-2011 period. This new reconstruction is based not on natural proxies but on a historical reanalysis of geopotential height fields. A climatic ensemble was reconstructed at daily resolution using the ANATEM methodology (Kuentz et al., 2015), a resampling method based on synoptic situation similarities between days (found by looking at the geopotential height reanalysis), with a sampling of observed climatic series for a given time period (the observation period) over a longer time period (the reconstruction period). Then, a rainfall-runoff model - previously calibrated on the observed period - was used to transform this climatic ensemble into a streamflow ensemble. The performances of the hydro-climatic reconstructions and of the rainfall-runoff model calibration were firstly evaluated over the observed period by comparing the reconstructions and the simulations with the observations. Secondly, the tree rings based on the ANATEM centennial reconstructions were compared and, finally, the long-term hydrological variability in the Caniapiscau Reservoir was discussed.

\section{Data}

\subsection{Datasets used for the climatic reconstructions}

\subsubsection{Geopotential height reanalysis}

The climatic reconstruction method applied in this study (fully detailed in the following section) is based on finding similarity between days at the synoptic scale. The similarity is based on geopotential height fields over a given spatial domain. A geopotential height is the height above sea level of a given pressure level. Note that for pressure levels close to sea level (typically $1000 \mathrm{hPa}$ ), the geopotential height can sometimes be negative. The analysis of geopotential height fields over a given domain describes the spatial distribution of high/low-pressure systems upon which similarity in between days can be measured. Several long-term geopotential height reanalyses have been produced during the last decade in order to study climate variability and climate change over the last century. The geopotential height reanalysis used in this study was drawn from the 20th Century Reanalysis V2c data, provided by the NOAA/OAR/ESRL PSD, Boulder, Colorado, USA, available from their website at http://www.esrl.noaa.gov/psd/ (Compo et al., 2011). This global reanalysis (hereafter denoted 20CR), assimilat- 
ing only surface observations of synoptic pressure, monthly sea surface temperature, and sea ice distribution, spans the period of 1851 to 2011, with a 6-hourly temporal resolution and a $2^{\circ}$ spatial resolution. For each day, two levels were considered here: $1000 \mathrm{hPa}$ at $0 \mathrm{~h}$ and $500 \mathrm{hPa}$ at $0 \mathrm{~h}$. The geopotential height fields were extracted over an area covering the entire province of Québec, with 221 grid points, as shown in Fig. 1a. Of the 56 ensemble members constituting the 20CR reanalysis, the members 1 to 5 were extracted and used over this region (see Sect. 3.3 for more details).

\subsubsection{The quest for centennial climatic series in northern Canada}

Centennial and continuous climatic series are rare in Canada, and almost non-existent in remote high-latitude regions, such as northern Québec (Cowtan and Way, 2014). In this study, there is a need for both consistent and very long (> 100 years) climatic series. Mekis and Vincent (2011) and Vincent et al. (2012) built two databases of "adjusted and homogenized" air temperature and precipitation series, respectively, both available at monthly and daily resolutions for all of Canada. These databases were specifically created for use as references in climate change impact studies. During their creation, care was taken to correct any errors that may surface, and to account for any shifts that may occur as a result of stations being moved or of changes in measurement instruments that may be present in the climatic series observed. Nevertheless, the average length of such series in northern Québec is 50 years, which is considered too short for this work or for any study concerning natural climatic variability.

In Québec, the few long climatic series ( $>100$ years) available are generally for large cities, which are all located in the southern part of the province. These series are rarely continuous at the daily timescale and are derived from different sources; as a result, producing good quality continuous series therefore requires a lot of work. For example, Slonosky (2014) compiled data from numerous sources (mainly from the cities of Québec and Montréal) to produce continuous daily temperature series for the St. Lawrence Valley region for the 1798-2010 period. In northeastern Canada, two sources of such historical data exist. First, the Moravian missionaries, who have been living among the Inuit in the Labrador coastal region since 1771, have measured and recorded climatic variables (Demarée et al., 2010). Secondly, interesting qualitative information for the Hudson Bay and the James Bay (northwestern Québec) 19th century climate are present in the Hudson's Bay Company trade post journals. Wilson (1988) compiled these data and produced summer temperature series and a wetness index for this region, and the series was then used by Bégin et al. (2015) as a reference series for comparisons with their climate reconstruction of the Canadian northeastern boreal forest. Unfortunately, no such data sources are present in the interior part of northern Québec.

\subsubsection{A reanalysis as local reference temperature series}

For the air temperature, the Berkeley Earth Surface Temperature (hereafter denoted BEST) analysis has been used, taken from the http://berkeleyearth.org/ website (Rohde et al., 2013). BEST is a gridded air temperature reanalysis for lands, starting in 1753 at the monthly resolution, and in 1880 at the daily resolution, with a $1^{\circ}$ spatial resolution. A daily catchment series has been assembled for the 1880-2011 period by averaging the $11 \mathrm{BEST}$ grid points covering the $\mathrm{Ca}-$ niapiscau Reservoir catchment, highlighted in Fig. 1. Note that this reanalysis was recently used in northeastern Canada by Way and Viau (2014), in their study of past air temperature variability in Labrador.

\subsection{Caniapiscau Reservoir catchment}

In Québec, $99 \%$ of the produced electricity comes from hydropower generation systems. The La Grande water resources system, located in northern Québec and operated by Hydro-Québec (HQ), is one of the most important hydropower systems in the world, with an installed capacity of $17418 \mathrm{MW}$ (the Three Gorges Dam is the most important hydropower system in the world with a total installed capacity of around $22000 \mathrm{MW}$ ). This system produces $50 \%$ of the total energy generated by HQ. The Caniapiscau hydroelectric reservoir catchment is the first dam of the $\mathrm{La}$ Grande operational chain (the Brisay power plant installed at the outlet of the Caniapiscau Reservoir is ranked as the ninth with an installed capacity of around $500 \mathrm{MW}$ ) and is a $37328 \mathrm{~km}^{2}$ snowmelt-dominated catchment. Figure 2 illustrates the hydro-climatic context of the Caniapiscau Reservoir catchment. The catchment elevation (SRTM data; Jarvis et al., 2008) ranges from around 500 to $900 \mathrm{~m}$ a.s.l., with the highest elevation areas located in the southern parts of the catchment. The daily streamflow series (Fig. 2a) and the monthly regimes (Fig. 2c) show the strong snow-dominated signature of the catchment, with an annual flood observed due to snowmelt during the month June. On average, the mean annual precipitation and runoff are around $800 \mathrm{~mm}$ (with around $300 \mathrm{~mm}$ falling as snow) and $650 \mathrm{~mm}$, respectively, on the Caniapiscau Reservoir, and the mean annual temperature is around $-3.6^{\circ} \mathrm{C}$. Catchment climatic data used in this study consist of daily series of minimum, mean, and maximum air temperature and of total precipitation, available for the 1950 to 2011 period. This dataset was produced by HQ, using kriging methods (Tapsoba et al., 2005). Daily streamflow series are available from 1962 to 2011. Note that only the 1962-1979 period was considered for the rainfallrunoff model calibration here, since the Caniapiscau Dam was built during the 1980-1982 period, and streamflow series available for 1982 to 2011 are naturalized flows produced by 
HQ. Nevertheless, this second period (1982-2011, mean annual values are plotted in grey in Fig. 2b) will be used as a validation period for the reconstruction.

\subsection{Reconstructed yearly streamflow series from tree rings}

Two yearly time series of Caniapiscau Reservoir flows have been used here for comparison at the centennial scale: (i) the series of annual flows proposed by Nicault et al. (2014) for the 1800-2000 period and (ii) the series of spring floods proposed by Boucher et al. (2011) for the 1850-1980 period. The first yearly time series was processed from continuous tree ring series derived from 20 black spruce (Picea mariana (Mill.) BSP) sites located within $200 \mathrm{~km}$ around the Caniapiscau Reservoir. Two reconstruction methods were used (partial least-squares (PLS) regression and best analogue methods), and the reconstructions obtained were combined in a single composite reconstruction. The second yearly time series was processed from ice-scar time series derived from a small lake located next to the Caniapiscau Reservoir and using tree ring densities obtained from 12 black spruce sites. A new transfer model technique based on generalized additive model (GAM) theory was used to process spring flood reconstructions.

\section{Methodology}

\subsection{General streamflow reconstruction methodology}

The general methodology consists of the reconstruction of an ensemble of daily climatic time series (with the ANATEM method) and of the transformation of this daily climatic ensemble into a daily streamflow ensemble, using a rainfallrunoff model. The ANATEM method (Kuentz et al., 2015) is built on the combination of two approaches: (i) the ANA (which stands for "ANAlogue") approach, which aims to find, for a given day, a given number of analogue days, based on the similarity of synoptic circulation (Obled et al., 2002; Schenk and Zorita, 2012), and (ii) the TEM (which stands for "TEMoin", the French word for "witness") approach, which is a basic regression model that uses a continuous and long-term reference (the witness) climatic series to reconstruct past climate. The ANATEM method thus allows the reconstruction of the climate of the past by combining synoptic information (ANA approach) with local climatic observations (TEM approach). Finally, this method allows the production of an ensemble of daily climatic time series by the selection of several analogues for any given day. For a complete description of the ANATEM method and an evaluation of its performance at the regional scale (French Alps), see Kuentz et al. (2015). The rainfall-runoff transformation is done here with GR4J (Perrin et al., 2003), a daily lumped continuous rainfall-runoff model, and its snowmelt routine, CemaNeige (Valéry et al., 2014a). GR4J and Ce-
maNeige have four and two free parameters to calibrate, respectively, using the observed streamflow data available on the studied catchment. The whole streamflow reconstruction methodology - performed in the R-project environment (2014, http://www.r-project.org/) - is carried out in four steps (see Fig. 3):

- Step 1: calibration of the rainfall-runoff (R-R) model. The rainfall-runoff model is calibrated on the observed streamflow data.

- Step 2: finding analogue dates (ANA). Synoptic states are compared in order to find analogue days for each day of the reconstruction period, amongst the days of the observation period.

- Step 3: reconstruction of a daily climatic ( $P$ and $T)$ ensemble (ANATEM). The best analogues obtained at step 2 are stochastically resampled and long-term reference climatic series are used (if available) to improve the resampled series.

- Step 4: reconstruction of a daily streamflow ensemble. The climatic ensemble is transformed into a streamflow ensemble using the rainfall-model parameter set obtained at step 1 .

These four steps are further detailed hereafter.

\subsection{Step 1: calibration of the rainfall-runoff model}

The GR4J (Perrin et al., 2003) rainfall-runoff model was used to transform the climatic ensemble into ensembles of streamflow time series. GR4J is an efficient and parsimonious (only four free parameters to be calibrated) daily lumped and continuous model, which, when it is combined with its snow accumulation and melt routine, CemaNeige (Valéry et al., 2014a), is well suited for the hydrological modelling of snow-dominated catchments. GR4J and CemaNeige (model pair hereafter denoted CemaNeigeGR4J) were recently evaluated over several catchments located in Québec (e.g., Seiller et al., 2012; Valéry et al., 2014b) and showed good modelling performances. The structure of the CemaNeigeGR4J model is presented in Fig. 3. GR4J is based on two nonlinear stores (production and routing stores) and a unit-hydrograph, while CemaNeige is a degree-day snow accounting routine, which divides the studied catchment into five elevation bands. CemaNeigeGR4J uses as inputs daily series of precipitation, minimal and maximal air temperatures, and a daily potential evapotranspiration series, calculated using Oudin et al. (2005) formula, designed for rainfall-runoff modelling. CemaNeigeGR4J produces daily streamflow series. GR4J and CemaNeige have four and two free parameters to calibrate, respectively. These six parameters - highlighted in Fig. 3 and described in Table 1 - were calibrated conjointly over the same calibration period using a local gradient search procedure, applied in combination with 

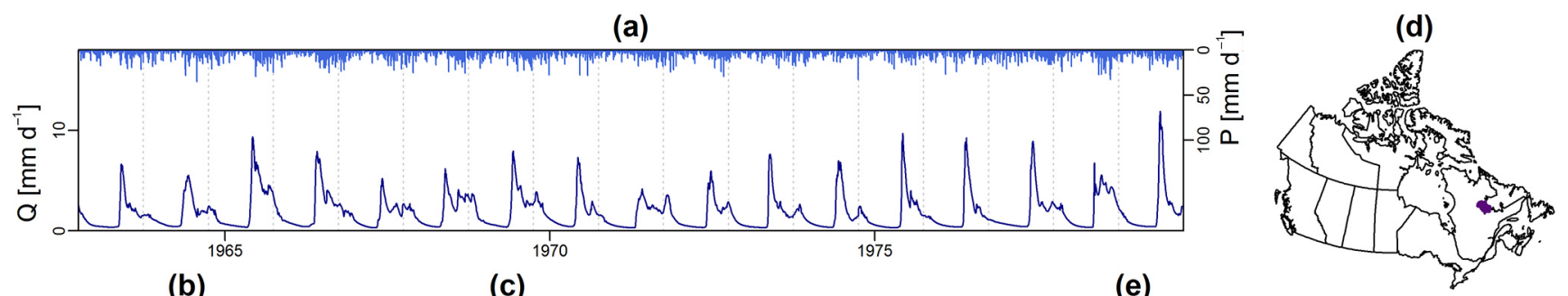

(b)
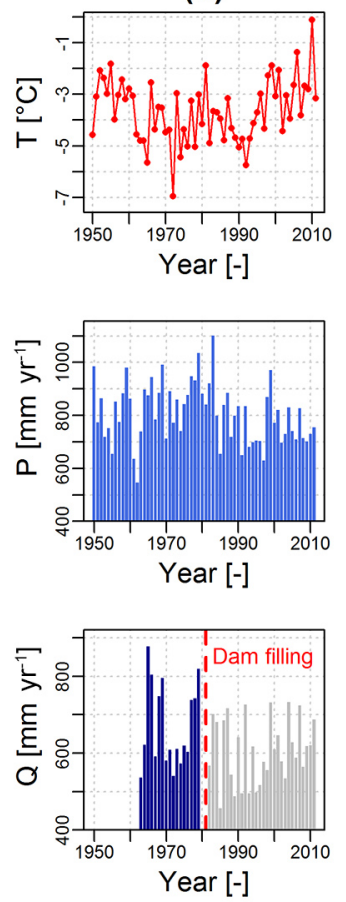

(c)
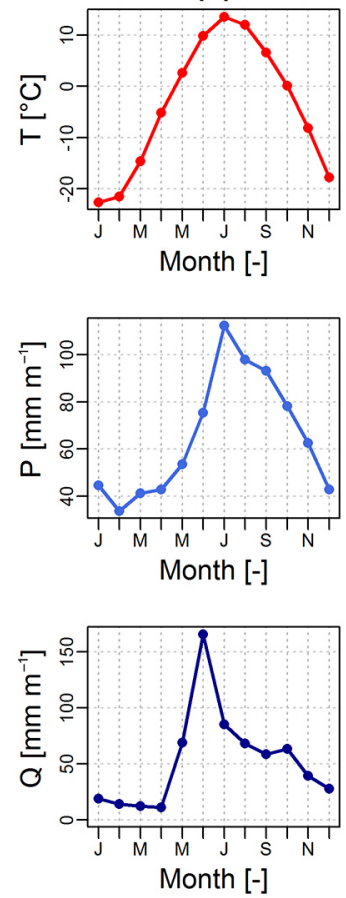

(e)

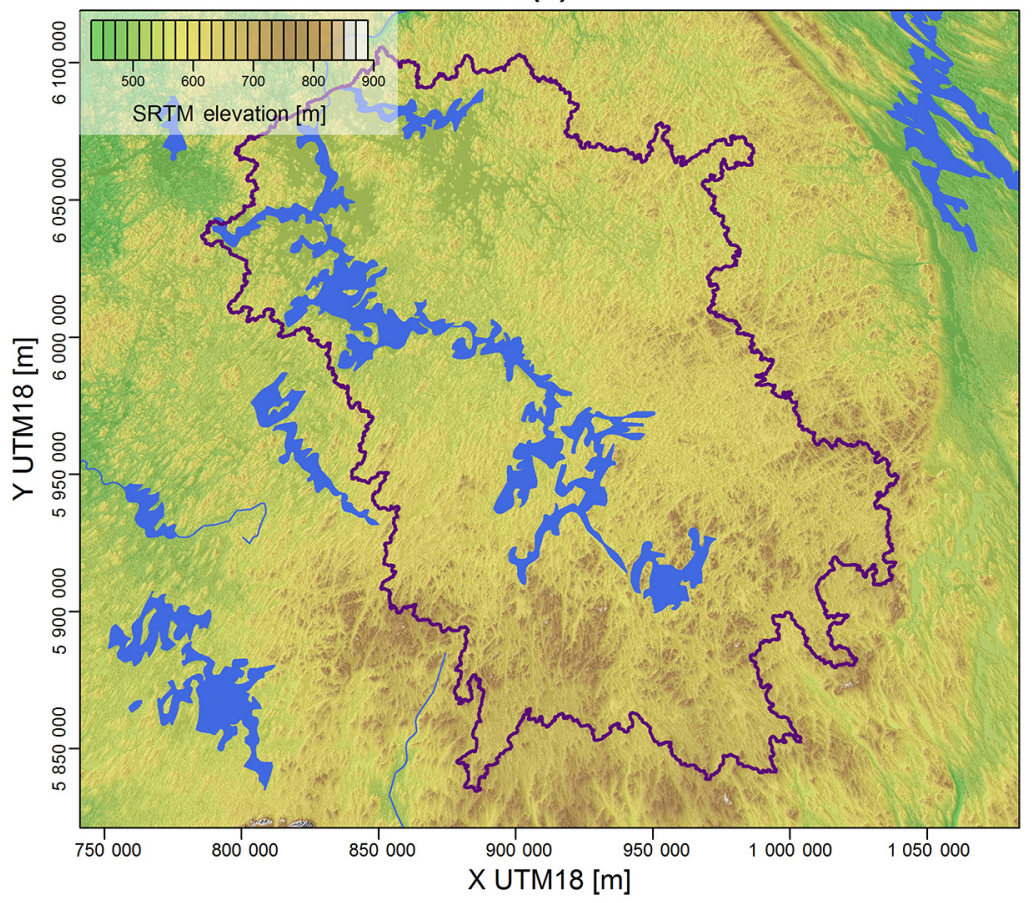

Figure 2. Hydro-climatic context of the Caniapiscau Reservoir catchment: (a) observed daily streamflow and precipitation time series used for the rainfall-runoff model calibration (1962-1979); (b) temperature, precipitation, and streamflow mean annual series; (c) temperature, precipitation, and streamflow monthly regimes; (d) catchment location within Canada; and (e) SRTM elevation data. Monthly regimes were calculated for the 1950-2011 period for temperature and precipitation, while for the 1962-1979 period, the calculations were for streamflow.

pre-screening of the parameter space (Perrin et al., 2008). The Kling and Gupta efficiency criterion (Gupta et al. (2009), hereafter denoted KGE) was used as objective function. The KGE criterion ranges between $-\infty$ and 1 (perfect simulation) and is estimated as follows:

$\mathrm{KGE}=1-\sqrt{(\beta-1)^{2}+(\alpha-1)^{2}+(r-1)^{2}}$,

where $\beta$ is the ratio between the means of the simulated and observed streamflow time series - this quantifies the simulation bias and ranges between 0 and $+\infty$ (values $>1$ indicate a model overestimation); $\alpha$ is the ratio between the standard deviations of the simulated and observed streamflow time series - this quantifies the ability of the simulation to reproduce the variability in the considered variable and ranges between 0 and $+\infty$ (values $>1$ indicate a model overdispersion); and $r$ is the coefficient of correlation between the simulated and the observed streamflow time series - this quantifies the ability of the simulation to reproduce the observed temporal variations in the considered variable and ranges between -1 and 1 (perfect correlation).

Using KGE limits the biases of both water balance and variability, while keeping a good temporal correlation. Note that, for each model simulation, the first simulated year was used as an initialization period and was not considered for the final performance evaluation. All the rainfall-runoff model outputs presented in the paper have been produced at the daily resolution by using both GR4J rainfall-runoff model and its snowmelt routine CemaNeige.

\subsection{Step 2: finding analogue dates (ANA)}

The ANA approach is a resampling method based on synoptic circulation similarities between days, with a sampling of observed climatic series for a given time period (here, 19502011, the observation period) over a longer time period (here, the 1880-2011 period, the reconstruction period). The synoptic information considered for the analogy is geopotential 


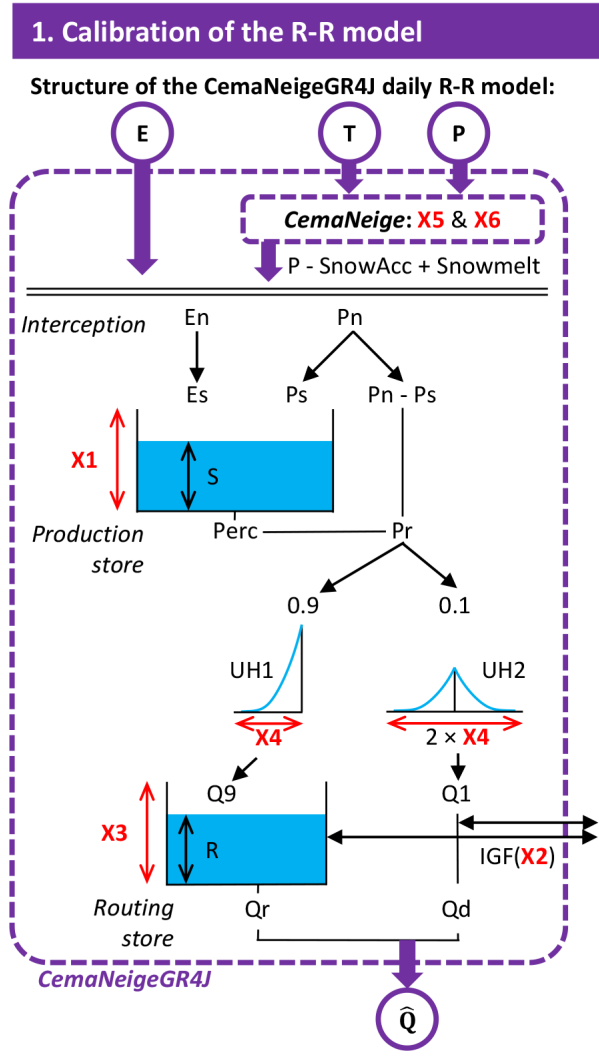

Calibration of the 6 parameters $(X 1, \ldots ., X 6)$ over the calibration period, with the KGE objective function.

\section{Finding analogue dates (ANA)}

Analysis of a 5-member ensemble (M1 to M5) of daily geopotential height fields (here at $500 \mathrm{hPa}$ and $1000 \mathrm{hPa}$ ) over a given region:

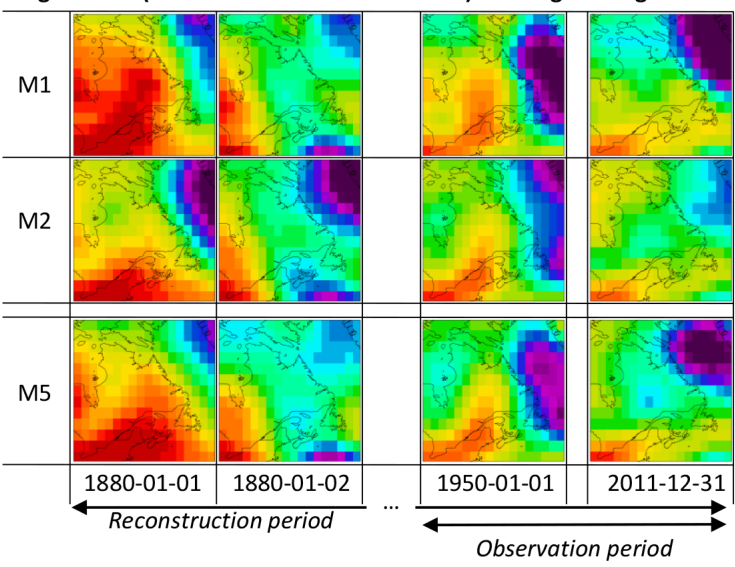

Calculation of $D_{T W}$ distances for finding analogues dates in the observation period:

$$
D_{T W}=D_{T W(7500 @ 0 h)}+D_{T W(7500 @ 24 h)}+D_{T W(Z 1000 @ 0 h)}+D_{T W(z 1000 @ 24 h)}
$$

For each day and each member $\mathrm{M}$, selection of $\mathbf{2 0}$ analogues dates:

\begin{tabular}{|c|c|c|c|c|c|}
\hline & 1984-01-23 & $1959-02-13$ & & $1963-11-20$ & $2007-12-18$ \\
\hline M1 & $\begin{array}{c}1991-12-12 \\
\ldots .\end{array}$ & $\begin{array}{c}1961-01-11 \\
\ldots\end{array}$ & $\cdots$ & $\begin{array}{c}1957-02-06 \\
\ldots\end{array}$ & $\begin{array}{c}1989-11-05 \\
\ldots .\end{array}$ \\
\hline & $\begin{array}{l}1988-01-16 \\
1984-01-23\end{array}$ & $\begin{array}{l}1953-12-25 \\
1974-12-27\end{array}$ & & $\begin{array}{l}1975-01-06 \\
1963-11-20\end{array}$ & $\begin{array}{l}2007-12-19 \\
1979-11-19\end{array}$ \\
\hline M2 & $\begin{array}{c}1990-11-30 \\
\ldots \\
1957-02-02\end{array}$ & $\begin{array}{c}1961-01-11 \\
\ldots \\
1990-02-19\end{array}$ & $\cdots$ & $\begin{array}{c}1957-02-06 \\
\ldots \\
1988-01-29\end{array}$ & $\begin{array}{c}1971-11-13 \\
\ldots \\
1976-12-04\end{array}$ \\
\hline M5 & $\begin{array}{c}1984-01-23 \\
1989-01-13 \\
\ldots \\
1993-11-09 \\
\end{array}$ & $\begin{array}{c}1961-01-11 \\
1962-01-25 \\
\ldots \\
1965-11-04 \\
\end{array}$ & $\cdots$ & $\begin{array}{c}1963-11-20 \\
1957-02-06 \\
\ldots \\
1962-01-14 \\
\end{array}$ & $\begin{array}{c}2007-12-18 \\
1971-11-13 \\
\ldots \\
1958-11-16\end{array}$ \\
\hline
\end{tabular}

\section{Reconstruction of a daily climatic (P and T) ensemble (ANATEM)}

Resampling of observed climatic data using analogue dates (ANA) and correction of the obtained ensemble with a local regression model if long-term reference series are available (ANATEM, here applied for T):

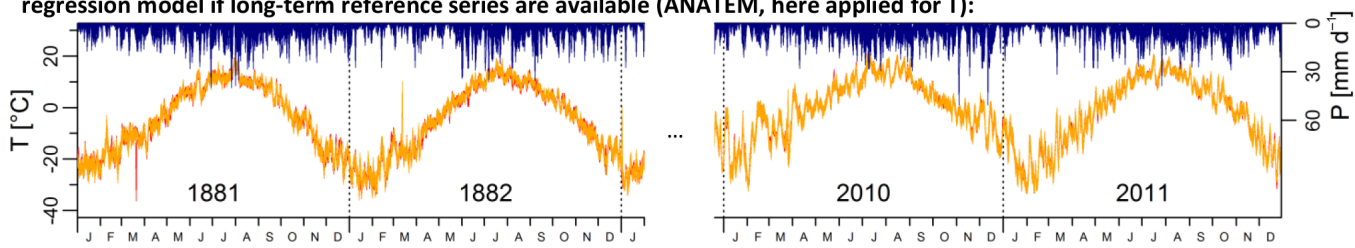

4. Reconstruction of a daily streamflow ensemble

Transformation of the climatic ensemble into a streamflow ensemble using the CemaNeigeGR4J (X1,...,X6) parameters:
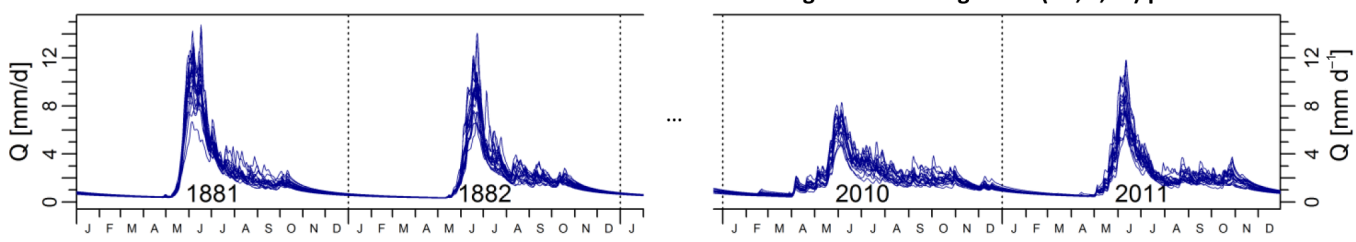

Figure 3. Illustration of the four-step methodology used for the reconstruction of a daily streamflow ensemble (R-R stands for rainfall-runoff, $E$ for potential evapotranspiration, $T$ for air temperature, $P$ for precipitation, and $Q$ for streamflow).

height fields. Here, each day is described by four geopotential height fields: (i) $1000 \mathrm{hPa}$ at $0 \mathrm{~h}$, (ii) $1000 \mathrm{hPa}$ at $24 \mathrm{~h}$, (iii) $500 \mathrm{hPa}$ at $0 \mathrm{~h}$, and (iv) $500 \mathrm{hPa}$ at $24 \mathrm{~h}$. The geopotential height fields are extracted over a large domain covering the studied area (see Sect. 2.1.1 and Appendix A). The metric used to rank the days in terms of analogy is the Tewe- les and Wobus (1954) distance (see Appendix B), which highlights similarities in terms of geopotential field shapes (Obled et al., 2002) and has been shown to provide better outcomes than what is obtained by using classical Euclidean distances in this framework (Wetterhall et al., 2005). Note that a seasonal constraint is imposed for the identification of 
Table 1. Description and final values of the six free parameters of the CemaNeigeGR4J model after being calibrated over the observed streamflow series of the Caniapiscau catchment.

\begin{tabular}{llr}
\hline Parameter & Description (and unit) & Calibrated values \\
\hline X1 (GR4J) & Capacity of the production store $(\mathrm{mm})$ & 405 \\
X2 (GR4J) & Water exchange coefficient $\left(\mathrm{mm} \mathrm{day}^{-1}\right)$ & 3.06 \\
X3 (GR4J) & Capacity of the nonlinear routing store $(\mathrm{mm})$ & 326 \\
X4 (GR4J) & Unit hydrograph time base (day) & 3.50 \\
X5 (CemaNeige) & Cold content factor $(-)$ & 0.004 \\
X6 (CemaNeige) & Snowmelt factor $\left(\mathrm{mm} \mathrm{day}^{-1}{ }^{\circ} \mathrm{C}^{-1}\right)$ & 3.66 \\
\hline
\end{tabular}

analogue days: the potential analogue days of a given day are the ones included in a 60-day period centred on the calendar studied day. Thus, analogues of a winter day are themselves winter days: for example, the potential analogue days for 1 January 1880 are all of the available days within the 1 December to 30 January period of the observation period (here, 1950-2011). Another constraint is also imposed for the identification of analogues in which no analogue can be selected if they are closer than 15 days from the chosen date. For example, the potential analogue days for 1 January 2000 are all of the available days within the 1 December to 30 January period of the observation period except the 15 December 1999 to 15 January 2000 period. The ranking of analogue days is based on the Teweles and Wobus distance (see Appendix B). For each studied day, a given number of $n$ analogues days is considered, thus generating a climatic ensemble of $n$ time series. Here, the 20 nearest analogue days were selected for each studied day and each 20CR member considered $(n=20)$. Table 2 illustrates the generation of this climatic ensemble by giving several analogue days obtained for three particular dates ( 1 and 2 January 1880 and 30 December 2011). For example, when considering member 1 of the 20CR (M1), the first analogue day of 1 January 1880 is 23 January 1984, the second analogue day is 12 December 1991, and the 20th analogue day is 16 January 1988 . Finally, $20 \times 5$ (5 members of the 20CR considered) daily climatic series were generated over the 1880-2011 period.

\subsection{Step 3: reconstruction of a daily climatic $(P$ and $T)$ ensemble}

Using ANA outputs, ANATEM aims to exploit the available long-term reference time series (hereafter denoted TEM) to improve the climatic reconstruction by applying a classical regression between ANA outputs and the reference series. In this study, the ANA approach was directly applied for the precipitation reconstruction (since no precipitation "witness" series was available), while the ANATEM approach was applied for the reconstruction of daily temperature (using the BEST daily temperature series). As in Kuentz et al. (2015), the local regression model (hereafter denoted LM), applied here for the temperature reconstruction, is based on an additive correction, modelled by a daily harmonic function. The parameters of this regression function were estimated over the observation period (here, 1950-2011) on the interannual mean monthly residuals of the differences between the catchment temperature series and the TEM series. The regression function has the following expression:

$\widehat{T}_{\mathrm{LM}}(d)=T_{\mathrm{TEM}}(d)+\beta(d)+\epsilon(d)$,

where $\widehat{T}_{\mathrm{LM}}(d)$ is the estimate of the air temperature for the day $d ; T_{\mathrm{TEM}}(d)$ is the value of the witness series temperature for the same day; $\beta(d)$ is the correction, depending on the calendar day of the year; and $\epsilon(d)$ is a residual assumed to have zero mean.

The ANATEM method was applied at the daily resolution over the 1880-2011 period. The ensemble of temperature values reconstructed for the day $d$ has the following expression:

$\left[\widehat{T}_{\text {ANATEM }}^{k}(d)\right]_{k=1, \ldots, n}=\widehat{T}_{\mathrm{LM}}(d)+\left[T\left(d_{k}\right)-\widehat{T}_{\mathrm{LM}}\left(d_{k}\right)\right]_{k=1, \ldots, n}$,

where $\left[\widehat{T}_{\text {ANATEM }}^{k}(d)\right]_{k=1, \ldots, n}$ is the ensemble of $n$ reconstructed temperature values for the target day $d, \widehat{T}_{\mathrm{LM}}(d)$ is the air temperature estimate obtained with the regression model for the day $d, d_{k}$ is the $k$ th analogue day selected for the day $d, T\left(d_{k}\right)$ is the observed temperature value for the $k$ th analogue day, $\widehat{T}_{\mathrm{LM}}\left(d_{k}\right)$ is the air temperature estimate obtained with the regression model for the $k$ th analogue day, and $n$ is the total number of analogue days (here $n=20$; see Sect. 2.1.1).

The final climatic ensemble is built with 100 precipitation (ANA outputs) and air temperature (ANATEM outputs) daily series over the 1880-2011 period. For each day, the 100 climatic values are obtained based on the 20 "closest" analogue days for each of the five 20CR members considered.

\subsection{Step 4: reconstruction of a daily streamflow ensemble}

Using the rainfall-runoff model parameter set obtained after calibration (step 1), the reconstructed climatic ensemble is finally transformed into one streamflow ensemble, available over the 1881-2011 period (1880 being used as an initialization period) at the daily temporal resolution. The final streamflow ensemble thus consists of 100 daily streamflow series over the 1881-2011 period. 
Table 2. Illustration of the analogue dates obtained with the ANA approach. Here, a sub-sample of the 20 analogue days of three particular dates (1 and 2 January 1880 and 30 December 2011) are given for each of the five 20CR members considered (M1 to M5). The ranking of analogue days is performed with Teweles and Wobus (1954) distances.

\begin{tabular}{llllll}
\hline 20CR member & ANA & $1880-01-01$ & $1880-01-02$ & $\ldots$ & $2011-12-30$ \\
\hline M1 & ANA1 & $1984-01-23$ & $1959-02-13$ & $\ldots$ & $2007-12-18$ \\
M1 & ANA2 & $1991-12-12$ & $1961-01-11$ & $\ldots$ & $1989-11-05$ \\
M1 & $\ldots$ & $\ldots$ & $\ldots$ & $\ldots$ & $\ldots$ \\
M1 & ANA20 & $1988-01-16$ & $1953-12-25$ & $\ldots$ & $2007-12-19$ \\
M2 & ANA1 & $1984-01-23$ & $1974-12-27$ & $\ldots$ & $1979-11-19$ \\
M2 & ANA2 & $1990-11-30$ & $1961-01-11$ & $\ldots$ & $1971-11-13$ \\
M2 & $\ldots$ & $\ldots$ & $\ldots$ & $\ldots$ & $\ldots$ \\
M2 & ANA20 & $1957-02-02$ & $1990-02-19$ & $\ldots$ & $1976-12-04$ \\
M3 & ANA1 & $1950-02-03$ & $1950-02-04$ & $\ldots$ & $2007-12-18$ \\
M3 & ANA2 & $1989-01-13$ & $1971-12-24$ & $\ldots$ & $1989-11-05$ \\
M3 & $\ldots$ & $\ldots$ & $\ldots$ & $\ldots$ & $\ldots$ \\
M3 & ANA20 & $1990-11-30$ & $1957-02-07$ & $\ldots$ & $2003-12-14$ \\
M4 & ANA1 & $1986-12-15$ & $1956-12-21$ & $\ldots$ & $2007-12-18$ \\
M4 & ANA2 & $2007-01-02$ & $1974-01-19$ & $\ldots$ & $1989-11-05$ \\
M4 & $\ldots$ & $\ldots$ & $\ldots$ & $\ldots$ & $\ldots$ \\
M4 & ANA20 & $2004-12-29$ & $1971-12-24$ & $\ldots$ & $1994-11-20$ \\
M5 & ANA1 & $1984-01-23$ & $1961-01-11$ & $\ldots$ & $2007-12-18$ \\
M5 & ANA2 & $1989-01-13$ & $1962-01-25$ & $\ldots$ & $1971-11-13$ \\
M5 & $\ldots$ & $\ldots$ & $\ldots$ & $\ldots$ & $\ldots$ \\
M5 & ANA20 & $1993-11-09$ & $1965-11-04$ & $\ldots$ & $1958-11-16$ \\
\hline
\end{tabular}

\subsection{Comparison of reconstructed series against observations}

In order to compare the reconstructed streamflow time series against observations, the reconstructed ensembles were first aggregated: a daily series was generated for each of the five 20CR members considered by averaging the 20 daily series constituting each ensemble. The five daily mean series are denoted $\overline{\text { ANA }}$ or $\overline{\text { ANATEM}}$, depending on the method used to produce them. The evaluation of the reconstruction performances was based on the three KGE components and its final values. For the reconstructed climatic time series, the computation of these four scores was carried out over the 19502011 period, at the daily timescale but also at the monthly timescale, in order to evaluate the intra-annual reconstruction performances, and at the yearly timescale, in order to evaluate interannual reconstruction performances. For the reconstructed streamflow ensemble, these scores were computed over mean annual flow values and mean May flow values over two time periods, 1963-1979 (rainfall-runoff model calibration period) and 1982 to 2011 (naturalized flows).

\section{Results}

\subsection{Rainfall-runoff model calibration performances (1963-1979)}

Over the 1963-1979 calibration period, the CemaNeigeGR4J model performs very well with a KGE value of 0.93 (rainfall-runoff simulations with KGE $>0.8$ are generally considered good). The values of the six calibrated parameters are detailed in Table 1. Figure 4 presents the performance of the CemaNeigeGR4J rainfall-runoff model over the calibration period (1963-1979). Simulated and observed quantiles of monthly streamflow show a strong correlation (Fig. 4a), with a limited overestimation of the lowest values by the rainfall-runoff model observed during the winter months (from January to April, Fig. 6b). The timing of the simulated regime is similar to the observed one. However, systematic limited biases are found, with an overestimation of the winter streamflow values (January to April) and of the spring flood values (June) and an underestimation of the streamflow values during the snowmelt period (July to October). The model is also able to simulate the general interannual variability in mean annual streamflow (Fig. 4c), with higher values for the 1964-1969 period and lower values for the 1970-1976 period, for example. Nevertheless, non-systematic biases are found for several years, with both underestimations (e.g., years 1964 and 1969) and overestimations (e.g., years 1972 and 1975) of mean annual streamflow values. Finally, the observed and modelled distributions of annual streamflow values are similar (Fig. 4d), with an overestimation of the lowest mean annual streamflow values. 

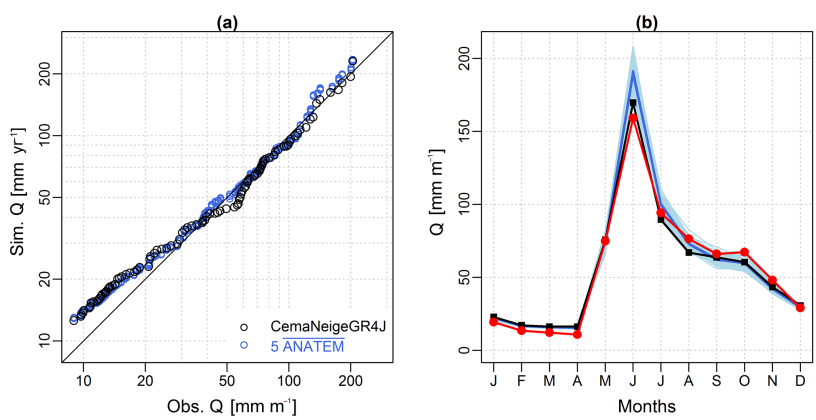

(c)
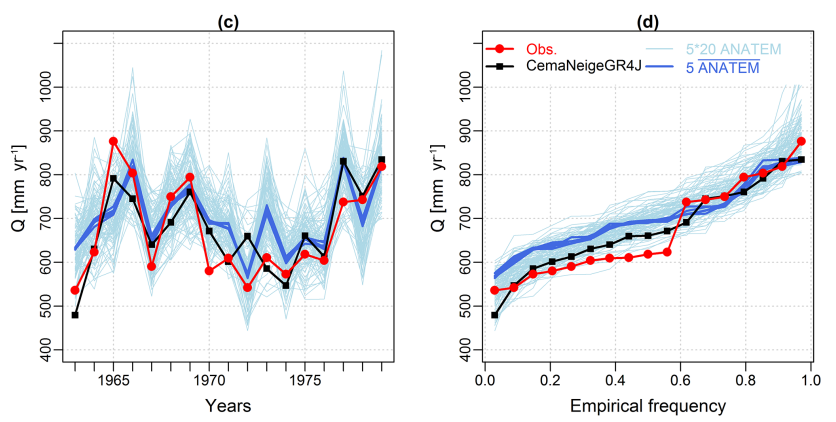

Figure 4. Performances of the CemaNeigeGR4J rainfall-runoff model (black) and of the ANATEM flow reconstruction (blue colours) evaluated over the calibration period of the rainfall-runoff model (1963-1979). (a) Monthly quantile-quantile plots (logarithmic scale), (b) observed and simulated monthly streamflow regime, (c) observed and simulated interannual streamflow variability, and (d) observed and simulated streamflow yearly mean distribution. The legend indicated on graph (d) is also valid for (b) and (c).

\subsection{Climatic reconstructions (1950-2011 and 1880-2011)}

In this section, the results of the climatic reconstruction are presented, first in terms of performance estimated over the observed period (1950-2011) and then in terms of centennial mean annual series (1880-2011).

\subsubsection{Performance of the climatic reconstructions over the observation period (1950-2011)}

Figure 5 compares the temperature reconstruction (using ANA and ANATEM outputs) and precipitation reconstruction (using ANA outputs) to the observations for the 19502011 period, in terms of monthly regimes and yearly value distributions. For temperature, the ANATEM reconstruction is excellent, in terms of both monthly regime and yearly mean value distribution. The ANA temperature reconstructions (in grey) show a limited performance for the coldest months (December and January) and for the warmest months (July and August) and thus highlight the importance of using the BEST temperature series through ANATEM, which successfully corrects the ANA outputs. The intra-variability in the ANATEM temperature ensemble is very limited.
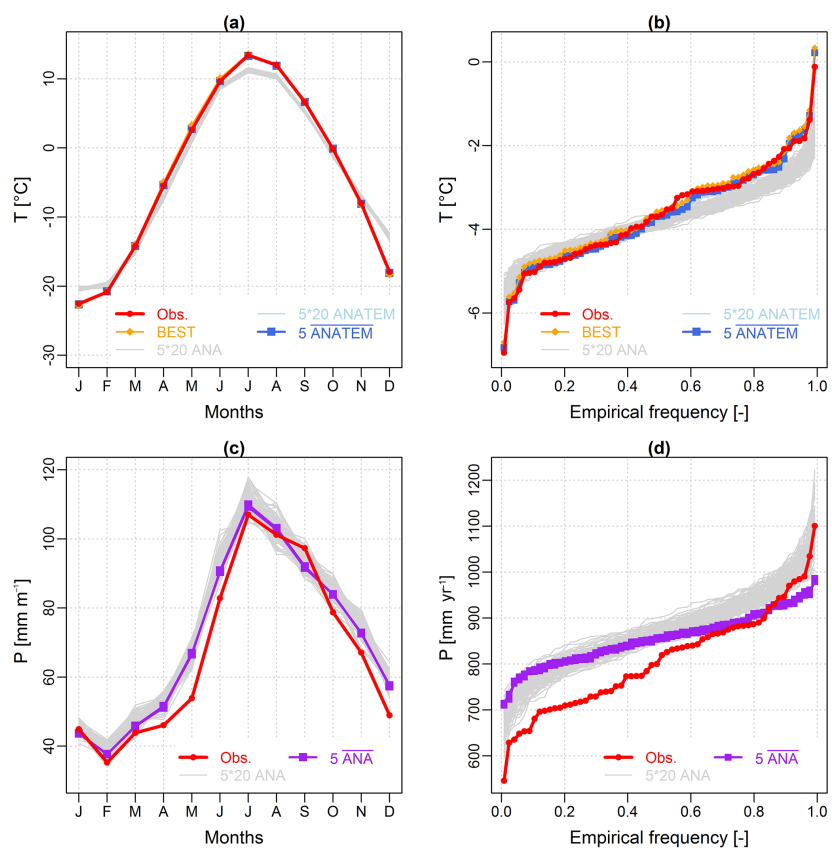

Figure 5. Monthly regimes (a, c) and yearly value distributions (b, d) for temperature (with ANA and ANATEM) and precipitation (with ANA) reconstructions and observations over the 19502010 period. Note that, for temperature monthly regime (a), the ANATEM simulations are similar to the observations, and thus ANATEM curves (blue) are not visible since they are below the observation curve (red).

The precipitation reconstruction is not as good as that of the temperatures. The timing of the monthly regime is well captured, with lowest monthly precipitations observed in February and the highest in July. However, an overestimation of the reconstructed precipitation is observed for all months, with the exception of January and September. Overall, a wet monthly bias of precipitation is found. This bias is also seen in the plot of the yearly value distributions (Fig. 5d), which show that a majority of the mean annual precipitation values are overestimated by the reconstruction. In terms of variability within the ensemble, the similarity of the five 20CR members $\overline{\mathrm{ANA}}$, in blue) shows that the uncertainty of the geopotential height field (quantified here through the consideration of the five members) has a negligible impact on the precipitation reconstruction over this time period and at these resolutions (yearly and monthly). The relatively large width of the ANA ensembles (grey envelopes) indicates that the uncertainty due to the selection of 20 analogue days has an impact on the precipitation reconstruction.

Figure 6 summarizes the climatic reconstruction performances at the daily, monthly, and yearly resolutions, both over the 1950-2011 period. For air temperature (Fig. 6a), and as previously indicated, the overall reconstruction performances are excellent for ANATEM outputs (KGE > 0.9) and limited for ANA outputs (KGE $>0.4)$. ANA outputs 

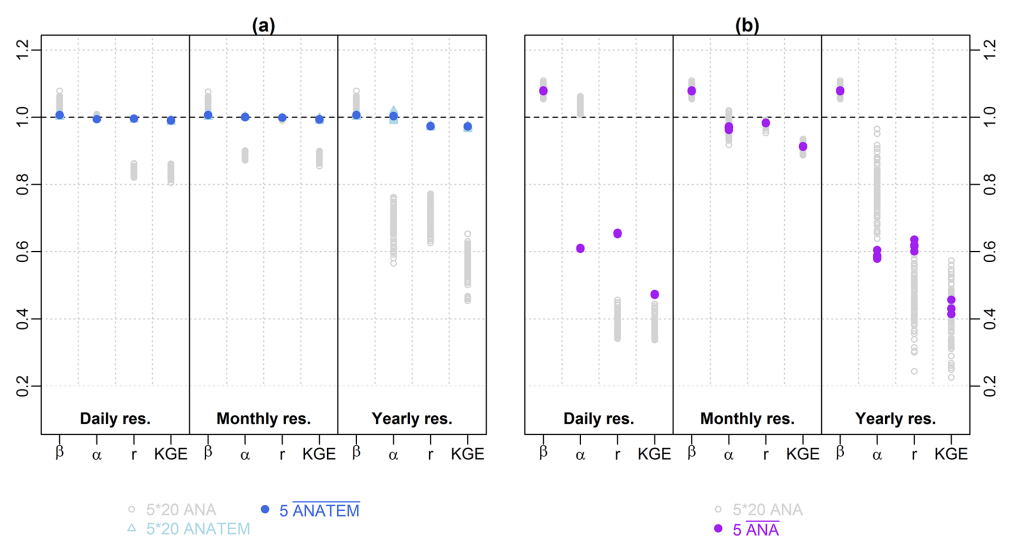

Figure 6. Daily, monthly, and yearly performances of the air temperature ANA and ANATEM reconstructions (a) and the ANA precipitation reconstructions (b), for the 1950-2011 period.

(grey points) are characterized by an overestimation $(\beta>1)$ tendency for the three resolutions and an underdispersion $(\alpha<1)$ tendency for the monthly and yearly resolutions. If the yearly temporal correlation is good at the daily and at the yearly resolutions, the temporal correlation is excellent at the monthly resolution $(r \approx 1)$. For precipitation (Fig. 6b), the overall reconstruction performance is better at the monthly resolution (KGE $>0.6)$ than at the daily (KGE ranging between 0.3 and 0.5 ) and yearly resolutions (KGE ranging between 0.2 and 0.6 ). The reconstructed time series show a clear overestimation bias, an underdispersion problem, and a limited temporal correlation at the three different resolutions. Averaging each ensemble of the considered 20CR members (blue points) results in better temporal correlations at the daily and yearly resolutions, but at the expense of too small a reconstructed variability.

\subsubsection{Centennial mean annual climatic series (1880-2011)}

Figure 7 shows the reconstructed climatic series over the entire studied period (1880-2011), at the yearly resolution. For temperature, the ANATEM reconstruction shows a very good fit to the observed series, with the exception of the first decade (1950-1960), when the reconstructed annual temperatures appear to be systematically lower than the observed annual temperature. ANA ensembles are larger than their ANATEM counterparts and perform worse in terms of mean annual temperature variability. The good performance of the ANATEM reconstruction is largely due to the BEST series, which is strongly correlated with the observed series at the annual resolution, except for the first observed decade. At the centennial scale, the reconstructed temperature time series are highly similar to the BEST series, showing that the entire temperature signal reconstructed is driven here by the BEST series. The ANATEM ensemble width is narrow at the annual timescale, as has already been seen for the monthly regime (Fig. 5a and b). The reconstruction shows an increase in the Caniapiscau catchment mean annual temperature over the last 130 years.

For mean annual precipitation, the ANA reconstruction does not perform as well, especially over the last two decades (1990-2010), where the reconstruction failed to reproduce the observed low values for the mean annual precipitation (compared to mean values over the entire observed period). A similar bias is found for the 1950-1965 period, while the variability in the mean annual precipitation values during the 1965-1985 period is well reproduced. Relatively, the precipitation reconstruction seems to be able to reproduce the wet-dry periods, but it fails to match the observed values. Considering the reconstruction at the centennial timescale, no significant trend is found for mean annual precipitation. Several periods are interesting, such as the sequence of wet and dry years around 1920. Finally, variability due to consideration of five 20CR members is seen until 1940, and seems to be higher for several time periods, such as the $1880-1890$ decade.

\subsection{Streamflow reconstructions (1962-2011 and 1881-2011)}

In this section, the results of the streamflow reconstructions are presented, first in terms of performance estimated over two time periods and then in terms of centennial series (annual mean flows and spring flood values).

\subsubsection{Performance of streamflow reconstruction over two observed periods (1962-1979 and 1981-2011)}

Using the five climatic ensembles produced by ANA (for precipitation) and ANATEM (for temperature) as inputs to the CemaNeigeGR4J rainfall-runoff model, five ensembles of 20 daily streamflow series were produced over the 1881 2011 period (the year 1880 is used as an initialization period 
(a)
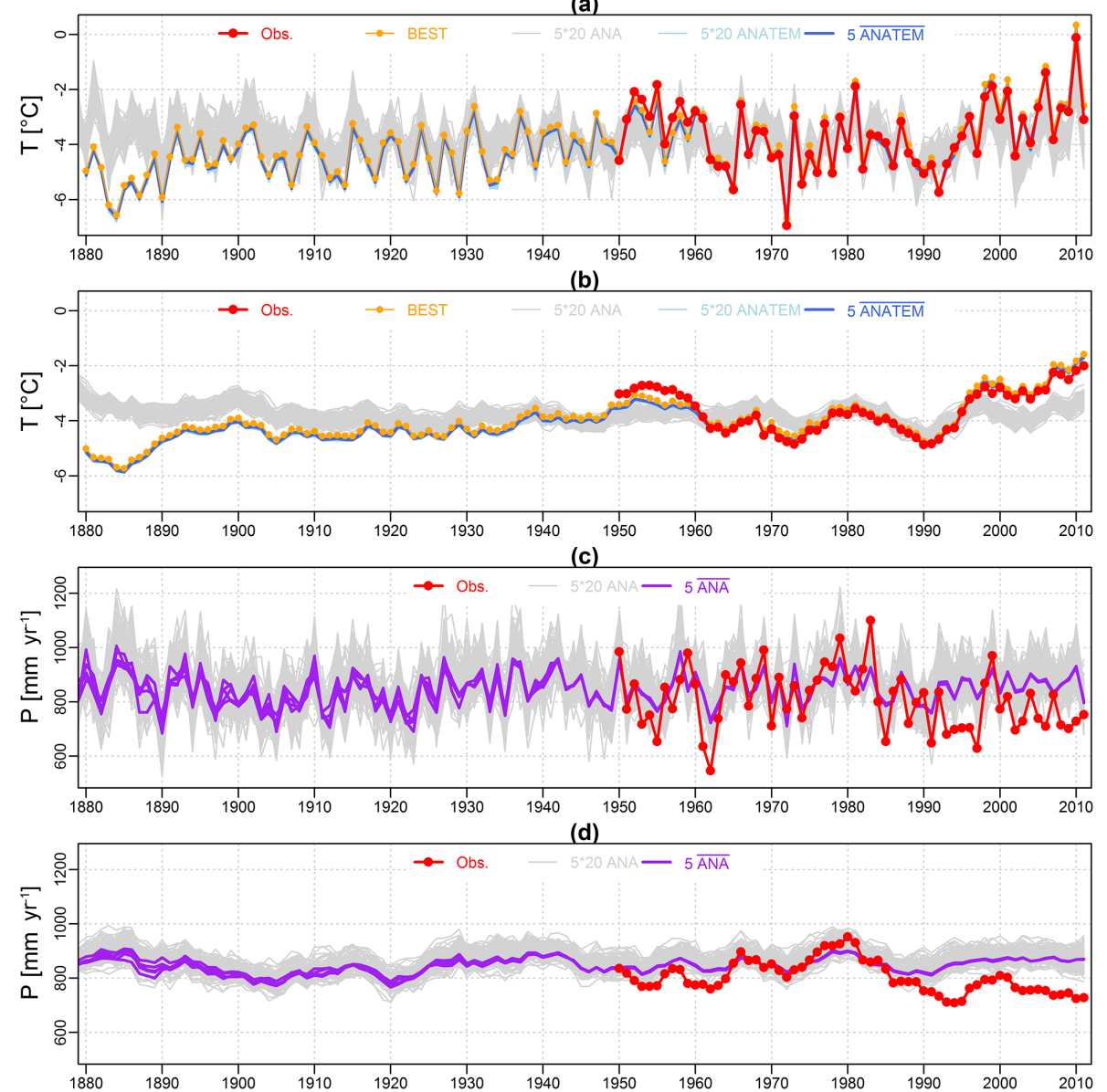

Figure 7. Interannual variability in reconstructed mean annual values of temperature (ANA and ANATEM outputs) and precipitation (ANA outputs) compared with observations over the 1880-2011 period. Panels (a) and (c) are raw yearly values, while (b) and (d) are 6-year running means of mean annual temperature and mean annual precipitation, respectively.

for the rainfall-runoff model). Figure 4 presents the performance of the streamflow reconstructions over the rainfallrunoff model calibration period (1963-1979). The obtained reconstructions have, logically, the same qualities and defaults characterizing the climatic reconstructions (presented in Sect. 4.2.1) and the rainfall-runoff model performance (presented in Sect. 4.1). Figure 4a is a quantile-quantile plot between observed and simulated mean monthly streamflows. Monthly correlations between observations and simulations are good, but they reveal a systematic overestimation of the lowest mean monthly streamflow values (winter months). A clear overestimation of the monthly flood peak (June) is also found (cf. Fig. 4b), due both to the rainfall-runoff model performance on this catchment and a general overestimation of the precipitation by the climatic reconstruction, as already shown in Fig. 5. Observed and simulated interannual variabilities are similar, but with an overestimation of the mean annual streamflow values by the reconstructions, especially for the years with relatively low mean annual streamflow values (1971-1976).
Figure 8 summarizes the performances of the streamflow reconstructions over two periods (1962-1979 and 19812011), in terms of mean annual streamflow values (Fig. 8a) and May monthly flow values (Fig. 8b). Overall KGE performances are limited to good for mean annual streamflow series and very good for the May monthly flow series. Again, an overestimation of mean annual flows is found for both periods. For May monthly flows, no specific trend is found for the first period, while a slight underestimation is observed for the second period. The performances of the dendrohydrological reconstructions are also evaluated and are shown in Figure 8, emphasizing that dendrohydrological reconstructions perform slightly better than ANATEM ones for the mean annual streamflow values while ANATEM reconstructions perform better than dendrohydrological ones for the May monthly flow values. 


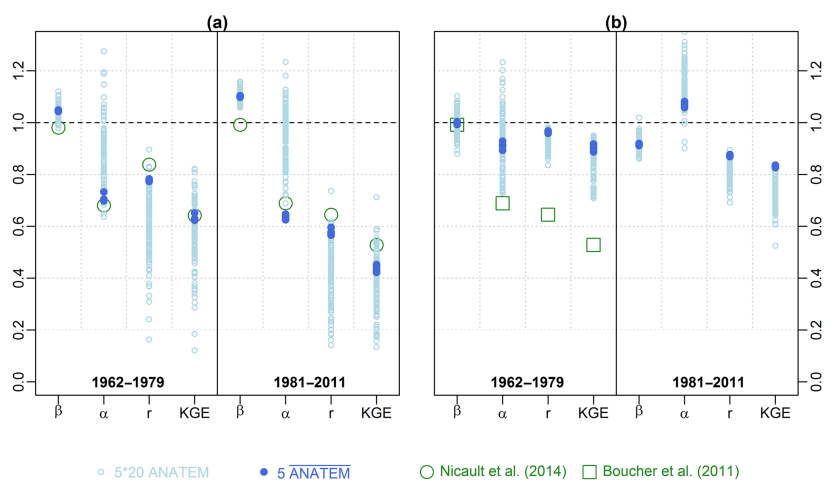

Figure 8. Streamflow reconstruction performances evaluated over two periods (1962-1979 and 1981-2011): (a) mean annual streamflow values and (b) May monthly flow values. Dendrohydrological reconstruction performances are also evaluated over the 1962-1979 and 1982-2001 periods for mean annual streamflow values (a) and the 1962-1979 period for May monthly flow values (b).

\subsubsection{Centennial mean annual flow reconstructions (1881-2011)}

Figure 9 presents the centennial ANATEM streamflow reconstruction and compares the reconstruction to observations and to the mean flow reconstruction proposed by Nicault et al. (2014) using tree rings. As shown in Fig. 4, a good correlation is found between the ANATEM reconstruction and observations for the 1963-1979 period. Considering the other streamflow observation time period (naturalized flows of 1982-2011), the correlation is weaker, with a general overestimation of the mean annual streamflow. At the centennial scale, a comparison between ANATEM and tree ring mean flow series reveals that the two series are not statistically different, since the ANATEM ensemble is within the tree ring confidence interval (green envelopes), except for the 19301940 period. For this period, and especially around 1940, ANATEM mean flow reconstructed values are significantly higher than tree ring ones. A significant variability in mean annual streamflow is simulated for the 130 past years. The two reconstructions agree for the 1880-1910 period, simulated as a period of decreasing mean annual streamflows, followed by a 10-year increasing period. The $1920-1950$ period shows differences between the two reconstructions, with ANATEM mean flows being larger than for tree rings. For the 1950-2011 period, the mean flow relative evolutions are similar, but the absolute values are different, with ANATEM values being systematically higher than tree ring values. This constant bias could be explained by the overestimation of precipitation over the record period. The year 1912 seems to be a "hydrologically interesting year", since it is simulated as a very wet year by tree rings but simulated as a dry year by ANATEM. Finally, as for the ANA precipitation reconstruction, the variability due to consideration of five $20 \mathrm{CR}$
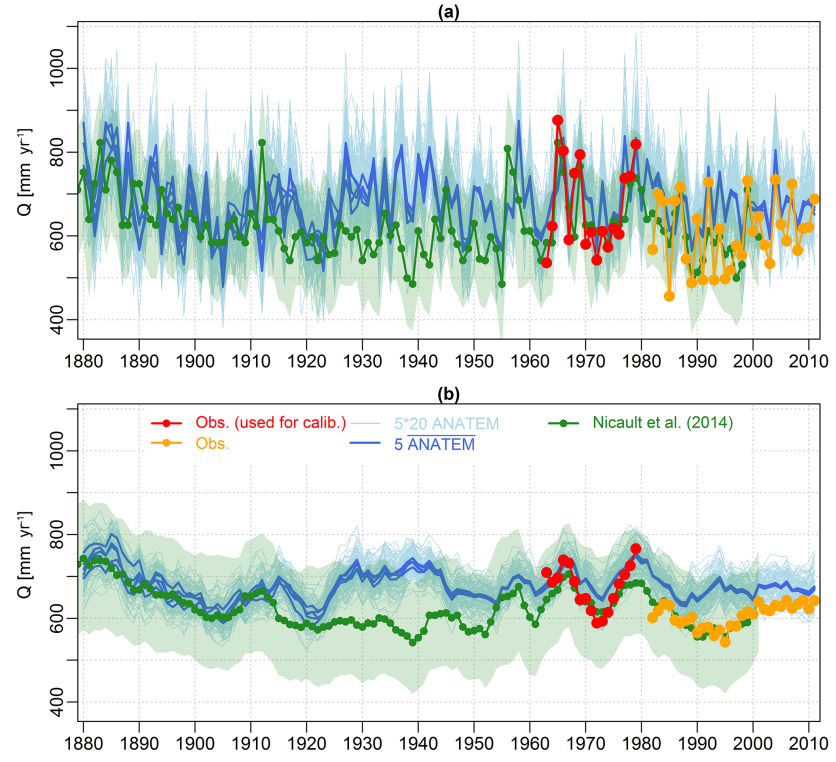

Figure 9. ANATEM mean flow reconstructions: comparison with observations and Nicault et al. (2014) tree ring series, 1881-2011 period. Panel (a) is raw yearly values, while (b) is 6-year running means of mean flows.

members is seen until the year 1940, and seems to be higher over the distant past.

\subsubsection{Centennial spring flood reconstruction (1881-2011)}

Finally, Fig. 10 presents the ANATEM centennial spring flood reconstruction compared to observations and to the reconstruction proposed by Boucher et al. (2011) using tree rings. For ANATEM and for the observed streamflow series, these annual series were constituted by estimating, for each year, the May monthly flow, since Boucher et al. (2011) produced a May streamflow reconstruction. The correlations between the ANATEM reconstruction and the observed series (1963-1979 and 1982-2011) are excellent and very good, respectively, and thus reproduce the increase in spring floods during the 1970-1980 period and then the decrease during the 1980-1990 period, finally followed by a slight increase and a stagnation over the two last decades. At the centennial scale, the two reconstructions appear to be significantly different for a long period of time, since the ANATEM ensemble is out of the tree ring confidence interval for the 1881-1920 period. Another significant difference exists over the 1950-1960 period, seen as a common decade by the tree ring reconstruction (reconstructed spring flood ranging from 47 to $\left.87\left(\mathrm{~mm} \mathrm{month}^{-1}\right)\right)$, while being seen as a highly variable hydrological decade for the ANATEM reconstruction, with high values for the first 5 years (around $110\left(\mathrm{~mm} \mathrm{month}^{-1}\right)$ for the $1950-1955$ period) and then two very low values (around $20\left(\mathrm{~mm} \mathrm{month}^{-1}\right)$ 


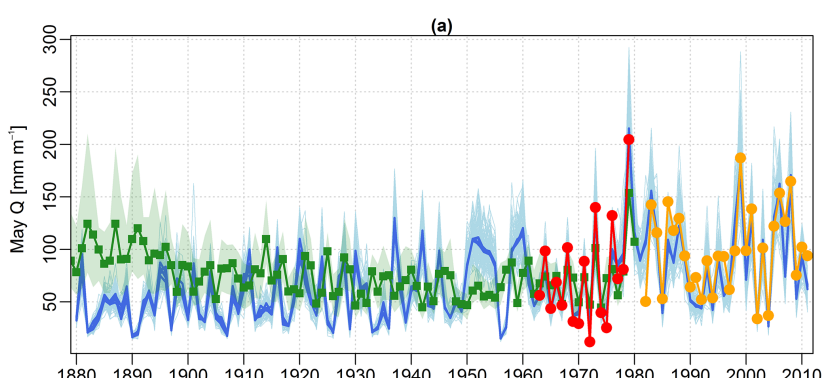

$\begin{array}{llllllllllllll}1880 & 1890 & 1900 & 1910 & 1920 & 1930 & 1940 & 1950 & 1960 & 1970 & 1980 & 1990 & 2000 & 2010\end{array}$

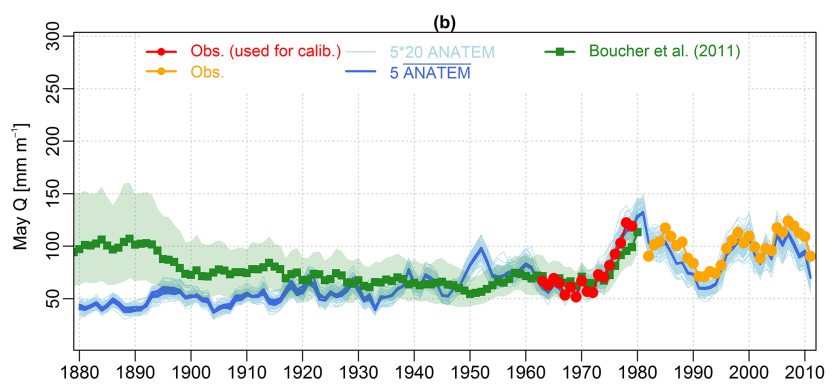

Figure 10. ANATEM spring flood reconstructions: comparison with observations and Boucher et al. (2011) tree ring series, 18812011 period. Panel (a) is raw yearly values, while (b) is 6-year running means of spring flood values.

for the 1956-1957 period), finally followed by three highvalue years (around $110\left(\mathrm{~mm} \mathrm{month}^{-1}\right)$ for the 1958-1960 period). Overall, the ANATEM reconstruction simulated an increasing trend of spring floods for the Caniapiscau catchment. This trend is related to the increasing temperature trend, as illustrated in Fig. 7.

\section{Discussion and conclusion}

In this study, a daily hydro-climatic reconstruction is proposed for the Caniapiscau Reservoir (northern Québec, Canada) for the 1881-2011 period. This reconstruction was generated by firstly applying the ANATEM method (Kuentz et al., 2015), combining large-scale atmospheric information (here the NOAA 20th Century geopotential height reanalysis; Compo et al., 2011) with local climatic observations when such series are available - to produce a daily ensemble of climatic series (precipitation and air temperature). Secondly, this climatic ensemble was used as input to a rainfallrunoff model (here GR4J (Perrin et al., 2003) and its snow accumulation and melt routine CemaNeige (Valéry et al., 2014a) previously calibrated in order to obtain a streamflow ensemble, at the daily resolution. The performances of the climatic reconstructions were quantified over the observed period (1950-2011) and showed very good performance for air temperature, in terms of both monthly regime and interannual variability. This excellent performance is due mainly to the use of a local reference temperature time series (here, a daily temperature time series extracted from the Berkeley Earth Surface Temperature analysis; Rohde et al., 2013).
For precipitation, no local reference climatic time series was available and the precipitation reconstructions are thus only a function of geopotential height field analogy. The precipitation reconstructions present a good performance in terms of regime, but with a somewhat limited ability to reproduce the observed annual values and interannual variability, combined with a systematic wet bias. The performance of the streamflow reconstruction was then compared to streamflow observations. This comparison showed a good performance, in terms of both monthly regimes and interannual variability, with a systematic overestimation of the mean annual streamflow values, due mainly to the wet bias of the precipitation reconstruction by the ANATEM method.

These newly produced reconstructions were then compared to two different reconstructions performed on the same catchment by using tree ring data series, one being focused on mean annual flows (Nicault et al., 2014) and the other on spring floods (Boucher et al., 2011). In terms of mean annual flows, the interannual variability in flows reconstructed by tree rings and ANATEM was similar (except for the decade 1930-1940), with significant changes seen in wetter and drier years. This variability seemed to be driven mainly by the variability in mean annual precipitation. In terms of spring floods, the interannual variabilities reconstructed by tree rings and by ANATEM were quite similar for the 19552011 period, but significantly different for the $1880-1940$ period. The ANATEM spring flood reconstruction showed an increasing trend over time, and this variability seemed to be driven by the variability in the mean annual temperature.

These results emphasize the need to apply different reconstruction methods on the same catchments. Indeed, such comparisons highlight potential differences between available reconstructions and, finally, allow a retrospective analysis of the proposed reconstructions of past hydroclimatological variabilities. In this study, two very different reconstruction methods were applied on the same catchment, revealing several periods where the two reconstructed streamflow series differ considerably. Thus, in terms of mean annual flows, the year 1922 and the decade 1930-1940 appear to be particularly dry and wet, respectively, when reconstructed with the ANATEM method, while they are simulated as particularly wet and dry when reconstructed using tree ring proxies. In terms of spring floods, the two reconstruction methods are in disagreement for the 1950-1960 decade, simulated as a decade with wide variabilities by ANATEM, with short sequences of alternating high and low spring flood values, compared to the tree ring reconstruction. Further investigation is needed in order to understand the differences for these specific periods. Finding indications of particular hydro-climatic conditions at the regional scale through the analysis of documents, reports, or ad hoc measurements could represent a means of assessing the respective performances of each reconstruction method. More generally, the long-term signals of the spring flood reconstructions are different, with a clear increasing tendency for floods recon- 
structed with ANATEM, related to the mean annual temperature rise in this region through the studied decades. Further work is needed to investigate this difference between the two reconstructions.

The evaluation of the analogue performance revealed two main limitations for the precipitation reconstruction. Firstly, a general wet bias was found when the reconstructed precipitation time series were compared to observations, and therefore a similar bias was observed for streamflow reconstruction. A classical bias-correction method could be applied on the reconstructed precipitation time series in order to eliminate this bias. However, applying a bias correction method implies an additional error source which could be amplified when the streamflow is analyzed (Teng et al., 2015) and, even more importantly, raises the issue of the bias stationarity (e.g., Teutschbein and Seibert, 2013; Chen et al., 2015; Velázquez et al., 2015). Secondly, the interannual variability in mean annual precipitation is reproduced with limited performances on the Caniapiscau Reservoir catchment. The inability of the analogue approach to reproduce the interannual precipitation variability - already highlighted by Kuentz et al. (2015) over 22 French catchments - is due to the absence of a local reference climatic time series, unlike for temperature reconstruction, where a local temperature time series is used, and ensures that the simulated interannual temperature variability is reproduced efficiently. Finding an additional series which significantly improves the precipitation reconstruction is a major perspective of this work. The use of variables produced by the available reanalyses (e.g., relative humidity, precipitable water content) for finding analogue dates will be investigated, along with the testing of time series of local pressure measurements. For example, Caillouet et al. (2016) showed that adding the sea surface temperature variable to the temperature, geopotential, vertical velocity, and humidity for finding analogue dates significantly improves the reconstruction of air temperature and precipitation over France.

In this study, most of the ANA approach options used to find analogue days were defined by looking at previous applications of the same methodology (e.g., Horton et al., 2012; Chardon et al., 2014) and by sensitivity analyses (results partially shown in Appendix A). The sensitivity of the final reconstructions to these options (size of the geopotential height domain extension (see Appendix A), choice of the geopotential height levels studied, number of analogue days, etc.) could be further investigated in a future work. Interestingly, the uncertainty due to the use of five members of the 20CR reanalysis appears to be limited, and even null from 1940 onward. See, for example, Fig. 9, which presents the centennial ANATEM streamflow reconstructions: it is impossible to distinguish the five ANATEM average series after 1940, emphasizing that considering five different members of the 20CR reanalysis as inputs of the reconstruction method has a negligible impact on the reconstruction of the mean annual streamflow.
Finally, the reconstructed climatic time series are transformed into streamflow time series thanks to a daily rainfallrunoff model, previously calibrated over the relatively short observation period (with very good calibration performances). The use of one model, one objective function, and one parameter set is questionable. Quantifying the sensitivity of the obtained reconstruction to the hydrological modelling assumptions made was out of the scope of this paper but definitively deserves further research, especially considering the issue of uncertainty due to rainfall-runoff model parameters in a changing climate. Thus, numerous authors highlighted that calibrated parameters of rainfall-runoff models are dependent on the climate of the calibration period and that performance decreases when applied over periods where the climate differs from that of calibration period (e.g., Merz et al., 2011; Coron et al., 2012; Brigode et al., 2013b). Thus, testing different calibration strategies (e.g., bootstrap calibration used by Brigode et al., 2015), testing particular objective functions especially devoted to the final study objective (e.g., studying mean annual streamflow), and adapting the time step of the rainfall-runoff model to the objective would be interesting for future works.

The combination of the ANATEM reconstruction method with a rainfall-runoff model offers an interesting method for use in reconstructing hydro-climatic time series at a very fine resolution (here daily), which is usually needed in applying impact models (such as dam management models) and, finally, to discuss the climatic process, which significantly influences the hydrological decadal variability at the catchment scale. An interesting perspective would be to test this modelling approach on numerous other catchments, as well as focusing on regions where long and good quality hydroclimatic time series are available, thus giving the opportunity to quantitatively evaluate the reconstruction methodology over long time periods. Kuentz et al. (2013) thus reconstructed 110-year streamflow time series for 22 French catchments with a combination of the ANATEM reconstruction method and a daily rainfall-runoff model, reconstitutions which allowed for discussion of the hydro-climatic variability over the last century in the studied region (French Alps). Finally, these applications could also give interesting insights into regions where it is not sufficient to consider only climatic time series in explaining observed multi-decadal hydrological variability and could thus highlight other significant factors influencing hydrological variability that need to be quantified (e.g., changes in land use, urbanization, or hydrogeology).

Another way to evaluate the two reconstruction methods would be to use the hydro-climatic time series reconstructed by ANATEM as inputs for a tree diameter growth model (e.g., models developed and applied for black spruces (Picea mariana (Mill.) BSP) in Canada by Subedi and Sharma, 2013, and Huang et al., 2013) and to then compare the tree ring simulated through this growth model with the observed tree ring series. 


\section{Data availability}

The daily hydro-climatic reconstruction proposed in this paper is available from Pierre Brigode (pierre.brigode@unice.fr) by request. Data sets used in this study are available via the following links: http://www.esrl.noaa.gov/psd/data/gridded/ data.20thC_ReanV2c.html (Compo et al., 2011); http://berkeleyearth.org/source-files/ (Rohde et al., 2013); http://srtm.csi.cgiar.org/SELECTION/inputCoord.asp (Jarvis et al., 2008). 


\section{Appendix A}

Several tests have been performed for choosing the spatial domain to consider for the description of the geopotential height fields (see Brigode et al., 2013a and Radanovics et al., 2013, for similar approaches). Here, eight different spatial domains have been tested (domain numbered from 1 to 8 ). These domains, illustrated on Fig. A1a, are centred on the Caniapiscau catchment and are progressively larger. For each domain, a climatic reconstruction has been performed with the ANA method for the Caniapiscau catchment but also for 211 other Québec catchments of the $(\mathrm{cQ})^{2}$ database Guay et al. (2015). These reconstructions have been performed for the 1990-2010 period with only one member of the 20CR reanalysis. The performances of these different reconstructions have been evaluated by comparing observed series with reconstructed series looking at different precipitation and air temperature criterion. Fig. A1b presents the three criteria chosen to evaluate the precipitation reconstruction: (i) the correlation between observed and reconstructed annual precipitation series (first line; optimal value is 1), (ii) the correlation between observed and reconstructed daily precipitation series (second line; optimal value is 1), and (iii) the bias between observed and reconstructed precipitation series (last line; optimal value is 0 ). The box plots summarize the performances obtained over the 211 catchments, while the purple point highlights the performance obtained specifically over the Caniapiscau catchment. Domain no. 5 was finally chosen as a (subjective) compromise between having high correlation between reconstructed and observed precipitation series (at yearly and daily resolutions) and having low precipitation bias between reconstructed and observed series on both the studied catchment (Caniapiscau) and on other neighbouring Québec catchments. Thus, we believe that the methodology performed in this study could also be used for the reconstruction of streamflow series on other neighbouring catchments. Finally, Fig. A1c presents the spatial distribution of the three criterion values obtained within domain no. 5 . These maps reveal interesting spatial patterns, highlighting, for example, higher performances in terms of daily precipitation correlation obtained for northern catchments compared to southern catchments. It is out of the scope of this paper to discuss the spatial variability and the spatial patterns of the climatic reconstruction performances, but this issue definitively deserves further research.

\section{Appendix B}

The Teweles and Wobus (1954) distance (noted $D_{\text {TW }}$ hereafter) is used to find analogues to the synoptic circulation of a given day and thus to quantify the (di)similarity between two synoptic spatial configurations, each characterized by four geopotential height fields over a given spatial domain (see Appendix A): (i) $1000 \mathrm{hPa}$ at $0 \mathrm{~h}$, (ii) $1000 \mathrm{hPa}$ at $24 \mathrm{~h}$, (iii) $500 \mathrm{hPa}$ at $0 \mathrm{~h}$, and (iv) $500 \mathrm{hPa}$ at $24 \mathrm{~h}$. The fi-
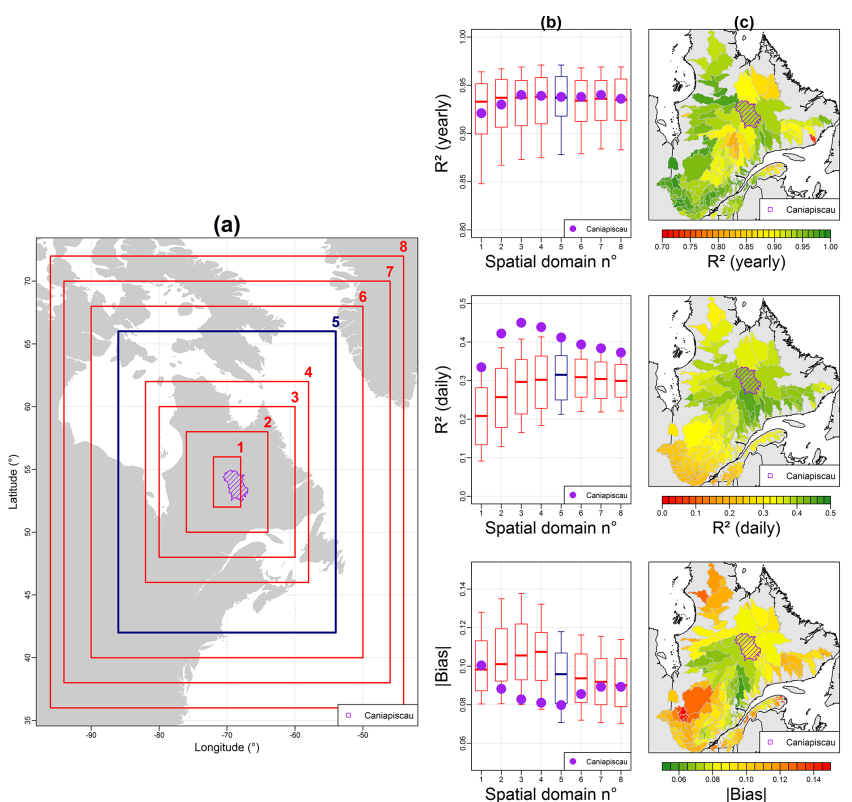

Figure A1. (a) Spatial extension of the eight geopotential height domains considered. (b) Performances of the precipitation ANA reconstruction estimated over the 1990-2010 period for 211 catchments of the $(\mathrm{cQ})^{2}$ database (the box plots are constructed with the 10th, 25th, 50th, 75th, and 90th percentiles). (c) Spatial distribution of the performances obtained with domain no. 5 over the 211 catchments of the $(\mathrm{cQ})^{2}$ database. The Caniapiscau catchment is highlighted in purple.

nal $D_{\text {Tw }}$ between a day A and another day B is the sum of four $D_{\mathrm{TW}}$ calculated for each of the four geopotential height fields. The distance between the geopotential height field $Z$ (e.g., $1000 \mathrm{hPa}$ at $0 \mathrm{~h}$ ) of day A and day B is calculated as follows:

$$
\begin{aligned}
D_{\mathrm{TW}, Z} & =100 \\
& \times \frac{\sum_{i=1}^{I-1} \sum_{j=1}^{J}\left|\Delta_{i, j}^{i, A}-\Delta_{i, j}^{i, B}\right|+\sum_{i=1}^{I} \sum_{j=1}^{J-1}\left|\Delta_{i, j}^{j, A}-\Delta_{i, j}^{j, B}\right|}{\sum_{i=1}^{I-1} \sum_{j=1}^{J} \max \left(\left|\Delta_{i, j}^{i, A}\right|,\left|\Delta_{i, j}^{i, B}\right|\right)+\sum_{i=1}^{I} \sum_{j=1}^{J-1} \max \left(\left|\Delta_{i, j}^{j, A}\right|,\left|\Delta_{i, j}^{j, B}\right|\right)},
\end{aligned}
$$

where $\Delta_{i, j}^{i, A}=Z_{i+1, j}^{A}-Z_{i, j}^{A}$ is the geopotential gradient of a west-east direction starting from a point $(i, j)$ for day A and $\Delta_{i, j}^{j, A}=Z_{i, j+1}^{A}-Z_{i, j}^{A}$ is the geopotential gradient of a southnorth direction starting from a point $(i, j)$ for day A.

This distance is thus focused on the synoptic circulation gradients (south-north and west-east directions) and not on the absolute geopotential height values. $D_{\mathrm{TW}}$ ranges from 0 (for two identical fields) to 200 (for two opposite fields). 
Acknowledgements. Support for the 20th Century Reanalysis Project version $2 \mathrm{c}$ dataset was provided by the US Department of Energy, Office of Science Biological and Environmental Research (BER), and by the National Oceanic and Atmospheric Administration Climate Program Office. Catherine Guay (IREQ) is thanked for the $(\mathrm{cQ})^{2}$ data and Hydro-Québec Production is thanked for the naturalized flows of the Caniapiscau Reservoir. Support from the Ouranos Consortium and from Quebec's Ministère de l'Économie, de la Science et de l'Innovation (PSR-SIIRI-183) is greatly acknowledged. The authors thank the two reviewers and the editor, who provided constructive comments on an earlier version of the manuscript, which helped clarify the text.

Edited by: E. Zorita

Reviewed by: two anonymous referees

\section{References}

Allen, K., Nichols, S., Evans, R., Cook, E., Allie, S., Carson, G., Ling, F., and Baker, P.: Preliminary December-January inflow and streamflow reconstructions from tree-rings for western Tasmania, southeastern Australia, Water Resour. Res., 51, 54875503, doi:10.1002/2015WR017062, 2015.

Andréassian, V., Lerat, J., Le Moine, N., and Perrin, C.: Neighbors: Nature's own hydrological models, J. Hydrol., 414-415, 49-58, doi:10.1016/j.jhydrol.2011.10.007, 2012.

Arsenault, R. and Brissette, F.: Continuous streamflow prediction in ungauged basins: The effects of equifinality and parameter set selection on uncertainty in regionalization approaches, Water Resour. Res., 6135-6153, doi:10.1002/2013WR014898, 2014.

Bégin, C., Gingras, M., Savard, M. M., Marion, J., Nicault, A., and Bégin, Y.: Assessing tree-ring carbon and oxygen stable isotopes for climate reconstruction in the Canadian northeastern boreal forest, Palaeogeogr. Palaeocl., 423, 91-101, doi:10.1016/j.palaeo.2015.01.021, 2015.

Boucher, E., Ouarda, T. B. M. J., Bégin, Y., and Nicault, A.: Spring flood reconstruction from continuous and discrete tree ring series, Water Resour. Res., 47, W07516, doi:10.1029/2010WR010131, 2011.

Bradley, R. S.: Paleoclimatology: reconstructing climates of the Quaternary, Academic Press, San Francisco, USA, 1999.

Brigode, P., Bernardara, P., Gailhard, J., Garavaglia, F., Ribstein, P., and Merz, R.: Optimization of the geopotential heights information used in a rainfall-based weather patterns classification over Austria, International J. Climatol., 33, 1563-1573, doi:10.1002/joc.3535, 2013a.

Brigode, P., Oudin, L., and Perrin, C.: Hydrological model parameter instability: A source of additional uncertainty in estimating the hydrological impacts of climate change?, J. Hydrol., 476, 410-425, doi:10.1016/j.jhydrol.2012.11.012, 2013 b.

Brigode, P., Paquet, E., Bernardara, P., Gailhard, J., Garavaglia, F., Ribstein, P., Bourgin, F., Perrin, C., and Andréassian, V.: Dependence of model-based extreme flood estimation on the calibration period: case study of the Kamp River (Austria), Hydrolog. Sci. J., 60, 1424-1437, doi:10.1080/02626667.2015.1006632, 2015.

Caillouet, L., Vidal, J.-P., Sauquet, E., and Graff, B.: Probabilistic precipitation and temperature downscaling of the Twentieth Century Reanalysis over France, Clim. Past, 12, 635-662, doi:10.5194/cp-12-635-2016, 2016.
Chardon, J., Hingray, B., Favre, A.-C., Autin, P., Gailhard, J., Zin, I., and Obled, C.: Spatial Similarity and Transferability of Analog Dates for Precipitation Downscaling over France, J. Climate, 27, 5056-5074, doi:10.1175/JCLI-D-13-00464.1, 2014.

Chen, J., Brissette, F. P., and Lucas-Picher, P.: Assessing the limits of bias-correcting climate model outputs for climate change impact studies, J. Geophys. Res.-Atmos., 120, 11231136, doi:10.1002/2014JD022635, 2015.

Compo, G. P., Whitaker, J. S., Sardeshmukh, P. D., Matsui, N., Allan, R. J., Yin, X., Gleason, B. E., Vose, R. S., Rutledge, G., Bessemoulin, P., Brönnimann, S., Brunet, M., Crouthamel, R. I., Grant, A. N., Groisman, P. Y., Jones, P. D., Kruk, M. C., Kruger, A. C., Marshall, G. J., Maugeri, M., Mok, H. Y., Nordli, Ø., Ross, T. F., Trigo, R. M., Wang, X. L., Woodruff, S. D., and Worley, S. J.: The Twentieth Century Reanalysis Project, Q. J. Roy. Meteor. Soc., 137, 1-28, doi:10.1002/qj.776, 2011 (data available at: http://www.esrl.noaa.gov/psd/data/gridded/data.20thC_ ReanV2c.html).

Coron, L., Andréassian, V., Perrin, C., Lerat, J., Vaze, J., Bourqui, M., and Hendrickx, F.: Crash testing hydrological models in contrasted climate conditions: an experiment on 216 Australian catchments, Water Resour. Res., 48, W05552, doi:10.1029/2011WR011721, 2012.

Cowtan, K. and Way, R. G.: Coverage bias in the HadCRUT4 temperature series and its impact on recent temperature trends, Q. J. Roy. Meteor. Soc., 140, 1935-1944, doi:10.1002/qj.2297, 2014.

Crooks, S. M. and Kay, A. L.: Simulation of river flow in the Thames over 120 years: Evidence of change in rainfallrunoff response?, J. Hydrol.-Regional Studies, 4, 172-195, doi:10.1016/j.ejrh.2015.05.014, 2015.

Demarée, G. R., Ogilvie, A. E., and Csonka, Y.: The Inuit of Labrador/Nunatsiavut, the Moravian Brethren, and Connections with French-Speaking Switzerland, Journal of the North Atlantic, 3, 24-30, doi:10.3721/037.003.0106, 2010.

George, S. S. and Nielsen, E.: Palaeoflood records for the Red River, Manitoba, Canada, derived from anatomical tree-ring signatures, Holocene, 13, 547-555, doi:10.1191/0959683603hl645rp, 2003.

Global Runoff Data Centre (GRDC): Tech. rep., Federal Institute of Hydrology (BfG), 56002, Koblenz, Germany, 2015.

Gray, S. T. and McCabe, G. J.: A combined water balance and tree ring approach to understanding the potential hydrologic effects of climate change in the central Rocky Mountain region, Water Resour. Res., 46, W05513, doi:10.1029/2008WR007650, 2010.

Guay, C., Minville, M., and Braun, M.: A global portrait of hydrological changes at the 2050 horizon for the province of Québec, Can. Water Resour. J./Revue canadienne des ressources hydriques, 40, 285-302, doi:10.1080/07011784.2015.1043583, 2015.

Gupta, H. V., Kling, H., Yilmaz, K. K., and Martinez, G. F.: Decomposition of the mean squared error and NSE performance criteria: Implications for improving hydrological modelling, J. Hydrol., 377, 80-91, doi:10.1016/j.jhydrol.2009.08.003, 2009.

Hernández-Henríquez, M. A., Mlynowski, T. J., and Déry, S. J.: Reconstructing the Natural Streamflow of a Regulated River: A Case Study of La Grande Rivière, Québec, Canada, Can. Water Resour. J./Revue canadienne des ressources hydriques, 35, 301316, doi:10.4296/cwrj3503301, 2010. 
Hirsch, R. M.: A comparison of four streamflow record extension techniques, Water Resour. Res., 18, 1081-1088, doi:10.1029/WR018i004p01081, 1982.

Horton, P., Jaboyedoff, M., Metzger, R., Obled, C., and Marty, R.: Spatial relationship between the atmospheric circulation and the precipitation measured in the western Swiss Alps by means of the analogue method, Nat. Hazards Earth Syst. Sci., 12, 777-784, doi:10.5194/nhess-12-777-2012, 2012.

Huang, J.-G., Bergeron, Y., Berninger, F., Zhai, L., Tardif, J. C., and Denneler, B.: Impact of Future Climate on Radial Growth of Four Major Boreal Tree Species in the Eastern Canadian Boreal Forest, PLoS ONE, 8, e56758, doi:10.1371/journal.pone.0056758, 2013.

Jandhyala, V. K., Liu, P., and Fotopoulos, S. B.: River stream flows in the northern Québec Labrador region: A multivariate change point analysis via maximum likelihood, Water Resour. Res., 45, W02408, doi:10.1029/2007WR006499, 2009.

Jarvis, A., Reuter, H. I., Nelson, A., and Guevara, E.: Hole-filled SRTM for the globe Version 4, available from the CGIAR-CSI SRTM $90 \mathrm{~m}$ Database, http://srtm.csi.cgiar.org/SELECTION/ inputCoord.asp (last access: July 2015), 2008.

Kuentz, A., Mathevet, T., Gailhard, J., Perret, C., and Andréassian, V.: Over 100 years of climatic and hydrologic variability of a Mediterranean and mountainous watershed: the Durance River, in: Cold and Mountain Region Hydrological Systems Under Climate Change: Towards Improved Projections, vol. 360, IAHS Publications, Gothenburg, Sweden, 19-25, 2013.

Kuentz, A., Mathevet, T., Gailhard, J., and Hingray, B.: Building long-term and high spatio-temporal resolution precipitation and air temperature reanalyses by mixing local observations and global atmospheric reanalyses: the ANATEM model, Hydrol. Earth Syst. Sci., 19, 2717-2736, doi:10.5194/hess-19-27172015, 2015.

Loaiciga, H. A., Haston, L., and Michaelsen, J.: Dendrohydrology and long-term hydrologic phenomena, Rev. Geophys., 31, 151$171,1993$.

Mekis, É. and Vincent, L. A.: An Overview of the Second Generation Adjusted Daily Precipitation Dataset for Trend Analysis in Canada, Atmos. Ocean, 49, 163-177, doi:10.1080/07055900.2011.583910, 2011.

Meko, D. M. and Woodhouse, C. A.: Application of Streamflow Reconstruction to Water Resources Management, in: Dendroclimatology, edited by: Hughes, M. K., Swetnam, T. W., and Diaz, H. F., no. 11 in Developments in Paleoenvironmental Research, Springer, the Netherlands, 231-261, doi:10.1007/978-14020-5725-0_8, 2011.

Merz, R., Parajka, J., and Blöchl, G.: Time stability of catchment model parameters: Implications for climate impact analyses, Water Resour. Res., 47 W02531, doi:10.1029/2010WR009505, 2011.

Montanari, A.: Hydrology of the Po River: looking for changing patterns in river discharge, Hydrol. Earth Syst. Sci., 16, 37393747, doi:10.5194/hess-16-3739-2012, 2012.

Nicault, A., Boucher, E., Bégin, C., Guiot, J., Marion, J., Perreault, L., Roy, R., Savard, M. M., and Bégin, Y.: Hydrological reconstruction from tree-ring multi-proxies over the last two centuries at the Caniapiscau Reservoir, northern Québec, Canada, J. Hydrol., 513, 435-445, doi:10.1016/j.jhydrol.2014.03.054, 2014.
Obled, C., Bontron, G., and Garçon, R.: Quantitative precipitation forecasts: a statistical adaptation of model outputs through an analogues sorting approach, Atmos. Res., 63, 303-324, doi:10.1016/S0169-8095(02)00038-8, 2002.

Oudin, L., Hervieu, F., Michel, C., Perrin, C., Andréassian, V., Anctil, F., and Loumagne, C.: Which potential evapotranspiration input for a lumped rainfall-runoff model?: Part 2 Towards a simple and efficient potential evapotranspiration model for rainfall-runoff modelling, J. Hydrol., 303, 290-306, doi:10.1016/j.jhydrol.2004.08.026, 2005.

Patskoski, J., Sankarasubramanian, A., and Wang, H.: Reconstructed streamflow using SST and tree-ring chronologies over the southeastern United States, J. Hydrol., 527, 761-775, doi:10.1016/j.jhydrol.2015.05.041, 2015.

Perreault, L., Parent, É., Bernier, J., Bobée, B., and Slivitzky, M.: Retrospective multivariate Bayesian change-point analysis: A simultaneous single change in the mean of several hydrological sequences, Stoch. Env. Res. Risk A., 14, 243-261, doi:10.1007/s004770000051, 2000.

Perreault, L., Garçon, R., and Gaudet, J.: Analyse de séquences de variables aléatoires hydrologiques à l'aide de modèles de changement de régime exploitant des variables atmosphériques, La Houille Blanche, 111-123, doi:10.1051/lhb:2007091, 2007.

Perrin, C., Michel, C., and Andréassian, V.: Improvement of a parsimonious model for streamflow simulation, J. Hydrol., 279, 275 289, doi:10.1016/S0022-1694(03)00225-7, 2003.

Perrin, C., Andréassian, V., Rojas Serna, C., Mathevet, T., and Le Moine, N.: Discrete parameterization of hydrological models: Evaluating the use of parameter sets libraries over 900 catchments, Water Resour. Res., 44, W08447, doi:10.1029/2007WR006579, 2008.

Radanovics, S., Vidal, J.-P., Sauquet, E., Ben Daoud, A., and Bontron, G.: Optimising predictor domains for spatially coherent precipitation downscaling, Hydrol. Earth Syst. Sci., 17, 4189-4208, doi:10.5194/hess-17-4189-2013, 2013.

R Core Team: R: A Language and Environment for Statistical Computing, R Foundation for Statistical Computing, Vienna, Austria, http://www.R-project.org/ (last access: July 2015), 2014.

Rohde, R., Muller, R. A., Jacobsen, R., Muller, E., Perlmutter, S., Rosenfeld, A., Wurtele, J., Groom, D., and Wickham, C.: A New Estimate of the Average Earth Surface Land Temperature Spanning 1753 to 2011, Geoinformatics \& Geostatistics: An Overview, 1, 1-7, doi:10.4172/2327-4581.1000101, 2013 (data available at: http://berkeleyearth.org/source-files/).

Saito, L., Biondi, F., Devkota, R., Vittori, J., and Salas, J. D.: A water balance approach for reconstructing streamflow using tree-ring proxy records, J. Hydrol., 529, 535-547, doi:10.1016/j.jhydrol.2014.11.022, 2015.

Schenk, F. and Zorita, E.: Reconstruction of high resolution atmospheric fields for Northern Europe using analog-upscaling, Clim. Past, 8, 1681-1703, doi:10.5194/cp-8-1681-2012, 2012.

Seiller, G., Anctil, F., and Perrin, C.: Multimodel evaluation of twenty lumped hydrological models under contrasted climate conditions, Hydrol. Earth Syst. Sci., 16, 1171-1189, doi:10.5194/hess-16-1171-2012, 2012.

Slonosky, V.: Historical climate observations in Canada: 18th and 19th century daily temperature from the St. Lawrence Valley, Quebec, Geoscience Data Journal, 1, 103-120, doi:10.1002/gdj3.11, 2014. 
Subedi, N. and Sharma, M.: Climate-diameter growth relationships of black spruce and jack pine trees in boreal Ontario, Canada, Glob. Change Biol., 19, 505-516, doi:10.1111/gcb.12033, 2013.

Tapsoba, D., Fortin, V., Anctil, F., and Haché, M.: Apport de la technique du krigeage avec dérive externe pour une cartographie raisonnée de l'équivalent en eau de la neige: Application aux bassins de la rivière Gatineau, Can. J. Civil Eng., 32, 289297, doi:10.1139/104-110, 2005.

Teng, J., Potter, N. J., Chiew, F. H. S., Zhang, L., Wang, B., Vaze, J., and Evans, J. P.: How does bias correction of regional climate model precipitation affect modelled runoff?, Hydrol. Earth Syst. Sci., 19, 711-728, doi:10.5194/hess-19-711-2015, 2015.

Teutschbein, C. and Seibert, J.: Is bias correction of regional climate model (RCM) simulations possible for nonstationary conditions?, Hydrol. Earth Syst. Sci., 17, 5061-5077, doi:10.5194/hess-17-5061-2013, 2013.

Teweles, J. and Wobus, H.: Verification of prognosis charts, B. Am. Meteorol. Soc., 35, 455-463, 1954.

Thorndycraft, V. R., Benito, G., Rico, M., Sopeña, A., Sánchez-Moya, Y., and Casas, A.: A long-term flood discharge record derived from slackwater flood deposits of the Llobregat River, NE Spain, J. Hydrol., 313, 16-31, doi:10.1016/j.jhydrol.2005.02.003, 2005.

Valéry, A., Andréassian, V., and Perrin, C.: "As simple as possible but not simpler": what is useful in a temperature-based snow-accounting routine? Part 2 - Sensitivity analysis of the Cemaneige snow accounting routine on 380 catchments, J. Hydrol., 517, 1176-1187, doi:10.1016/j.jhydrol.2014.04.058, 2014a.
Valéry, A., Andréassian, V., and Perrin, C.: "As simple as possible but not simpler": what is useful in a temperature-based snowaccounting routine? Part 1 - Comparison of six snow accounting routines on 380 catchments, J. Hydrol., 517, 1166-1175, doi:10.1016/j.jhydrol.2014.04.059, 2014b.

Velázquez, J. A., Troin, M., Caya, D., and Brissette, F.: Evaluating the Time-Invariance Hypothesis of Climate Model Bias Correction: Implications for Hydrological Impact Studies, J. Hydrometeorol., 16, 2013-2026, doi:10.1175/JHM-D-14-0159.1, 2015.

Vincent, L. A., Wang, X. L., Milewska, E. J., Wan, H., Yang, F., and Swail, V.: A second generation of homogenized Canadian monthly surface air temperature for climate trend analysis, J. Geophys. Res.-Atmos., 117, D18110, doi:10.1029/2012JD017859, 2012.

Way, R. G. and Viau, A. E.: Natural and forced air temperature variability in the Labrador region of Canada during the past century, Theor. Appl. Climatol., 121, 413-424, doi:10.1007/s00704-0141248-2, 2014.

Wetterhall, F., Halldin, S., and Xu, C.-Y.: Statistical precipitation downscaling in central Sweden with the analogue method, J. Hydrol., 306, 174-190, doi:10.1016/j.jhydrol.2004.09.008, 2005.

Wilson, C.: The summer season along the east coast of Hudson Bay during the nineteenth century. Part III: Summer thermal and wetness indices B. The indices, 1800-1900, Canadian Climate Centre Report 88-3, Environment Canada, Downsview, Ontario, Canada, 1988. 